\title{
RESEARCH
}

Open Access

\section{Efficient hepatic differentiation and regeneration potential under xeno-free conditions using mass-producible amnion- derived mesenchymal stem cells}

Jiwan Choi ${ }^{1,2,3}$, Seoon Kang ${ }^{1,2,3}$, Bitnara Kim²,3, Seongjun So ${ }^{1,2}$, Jongsuk Han ${ }^{1,2,3}$, Gyeong-Nam Kim ${ }^{1,4}$, Mi-Young Lee ${ }^{5}$, Seonae Roh', Ji-Yoon Lee ${ }^{6}$, Soo Jin Oh ${ }^{6}$, Young Hoon Sung ${ }^{1,4}$, Yeonmi Lee ${ }^{2,3}$, Sung Hoon Kim ${ }^{5^{*}}$ and Eunju Kang ${ }^{1,2,3^{*}}$ (D

\begin{abstract}
Background: Amnion-derived mesenchymal stem cells (AM-MSCS) are an attractive source of stem cell therapy for patients with irreversible liver disease. However, there are obstacles to their use due to low efficiency and xenocontamination for hepatic differentiation.

Methods: We established an efficient protocol for differentiating AM-MSCs into hepatic progenitor cells (HPCs) by analyzing transcriptome-sequencing data. Furthermore, to generate the xeno-free conditioned differentiation protocol, we replaced fetal bovine serum (FBS) with polyvinyl alcohol (PVA). We investigated the hepatocyte functions with the expression of mRNA and protein, secretion of albumin, and activity of CYP3A4. Finally, to test the transplantable potential of HPCs, we transferred AM-MSCs along with hepatic progenitors after differentiated days 11,12 , and 13 based on the expression of hepatocyte-related genes and mitochondrial function. Further, we established a mouse model of acute liver failure using a thioacetamide (TAA) and cyclophosphamide monohydrate (CTX) and transplanted AM-HPCs in the mouse model through splenic injection.

Results: We analyzed gene expression from RNA sequencing data in AM-MSCs and detected downregulation of hepatic development-associated genes including GATA6, KIT, AFP, c-MET, FGF2, EGF, and c-JUN, and upregulation of GSK3. Based on this result, we established an efficient hepatic differentiation protocol using the GSK3 inhibitor, CHIR99021. Replacing FBS with PVA resulted in improved differentiation ability, such as upregulation of hepatic maturation markers. The differentiated hepatocyte-like cells (HLCs) not only synthesized and secreted albumin, but also metabolized drugs by the CYP3A4 enzyme. The best time for translation of AM-HPCs was 12 days from the start of differentiation. When the AM-HPCs were transplanted into the liver failure mouse model, they settled in the damaged livers and differentiated into hepatocytes.
\end{abstract}

\footnotetext{
*Correspondence: kimsung@amc.seoul.kr; ekang@cha.ac.kr

${ }^{5}$ Department of Obstetrics and Gynecology, University of Ulsan College of

Medicine, Asan Medical Center, Seoul 05505, South Korea

'Department of Medical Science, Asan Medical Institute of Convergence

Science and Technology (AMIST), University of Ulsan College of Medicine,

Asan Medical Center, Seoul 05505, South Korea

Full list of author information is available at the end of the article
}

\section{$\triangle B M C$}

(c) The Author(s). 2021 Open Access This article is licensed under a Creative Commons Attribution 4.0 International License, which permits use, sharing, adaptation, distribution and reproduction in any medium or format, as long as you give appropriate credit to the original author(s) and the source, provide a link to the Creative Commons licence, and indicate if changes were made. The images or other third party material in this article are included in the article's Creative Commons licence, unless indicated otherwise in a credit line to the material. If material is not included in the article's Creative Commons licence and your intended use is not permitted by statutory regulation or exceeds the permitted use, you will need to obtain permission directly from the copyright holder. To view a copy of this licence, visit http://creativecommons.org/licenses/by/4.0/ The Creative Commons Public Domain Dedication waiver (http://creativecommons.org/publicdomain/zero/1.0/) applies to the data made available in this article, unless otherwise stated in a credit line to the data. 
Conclusion: This study offers an efficient and xeno-free conditioned hepatic differentiation protocol and shows that AM-HPCs could be used as transplantable therapeutic materials. Thus, we suggest that AM-MSC-derived HPCs are promising cells for treating liver disease.

Keywords: Amnion-derived mesenchymal stem cells, Differentiation, Hepatic progenitor, Xeno-free, GSK3 inhibitor, Polyvinyl alcohol

\section{Background}

The liver plays a key role in the detoxification of drugs, the synthesis of proteins and hormones, and supports glycogen and cholesterol metabolism. Liver failure can be the result of acute or chronic causes such as alcohol, toxic drugs, viral infection, and genetic factors [1]. Approximately 100,000 individuals per year are diagnosed with alcoholic liver disease and 12,000 people die only in the US [2].

Recently, advanced stem cell technologies have extended the resources of regenerative medicine, and stem cells are expected to replace liver transplantation in the foreseeable future [3]. To obtain transplant cells for liver disease, hepatocytes or hepatic progenitor cells [4], pluripotent stem cells (PSCs), such as induced pluripotent stem cells (iPSCs) [5] or embryonic stem cells (ESCs) [6], mesenchymal stem cells (MSCs) [7], hepatic progenitor cells isolated from the liver or derived from hepatocytes, or hepatocytes themselves, are used [8]. Until now, these sources have several limitations for clinical application. For example, iPSCs display a high risk of tumorigenicity and have lowefficiency differentiation ability, the use of ESCs is limited by their genetic background in terms of HLA types, MSCs have low differentiation ability, contamination with xenomaterial such as fetal bovine serum (FBS) or Matrigel, and there is limited access to enough number of natural liver progenitor cells.

We have reported that hepatocyte-like cells (HLCs) differentiated from adult human liver-derived stem cells (hLD-SCs) have good liver regeneration potential [9]. However, their obtained cell numbers from health donor individuals are limited and they are exposed to undefined animal-derived products such as FBS during differentiation [10].

Human amniotic membranes (AM) are high-yielding sources of stem cells [11]. Since the placenta is a temporary organ in which maternal and fetal cells occur together, fetal cells must be protected from the maternal immune system. For this reason, the expression of the major histocompatibility complex (MHC) is reduced in the placental membrane [12]. Moreover, placental membrane-derived stem cells have high proliferation rates, and differentiation abilities comparable to stem cells from other sources [13]. Especially, MSC-like cells isolated from the AM have been characterized in the previous studies in terms of multipotency, low tumorigenicity, immunomodulation, and antiinflammatory capacities [14]. Human AM-MSCs could be differentiated into typical mesenchymal lineages, such as osteocytes, chondrocytes, and adipocytes, and no tumorigenic conversion was observed [15]. Moreover, the immunomodulation and anti-inflammatory capacity of AM-MSCs had reported that cells display supportive function through paracrine effects [16].

FBS is a highly effective growth supplement for cell culture. However, there is batch-to-batch variability that may affect cell characteristics, and the risk of contamination with harmful pathogens in human transplantation studies [17, 18]. Accordingly, progressive attempts have been made to devise chemically defined xeno-free culture conditions for stem cells $[19,20]$.

In this study, we reexamined the characteristics of AMMSCs compared with the umbilical cord matrix (UCM)MSCs in terms of phenotype and gene expression. Moreover, we showed that AM-MSCs could become potentially useful donors by modifying the B2M gene. Next, after RNA expression analysis, we established an efficient protocol for differentiating AM-MSCs into HLCs by adding the GSK3 inhibitor, CHIR99021, and polyvinyl alcohol (PVA) instead of fetal bovine serum under gelatincoated plates. The gelatin-coated condition can promote the proliferation and growth of MSCs [21, 22]. Finally, we identified the optimum time for transplantation after initiating in vitro differentiation by measuring the expression of the carboxypeptidase $\mathrm{M}$ (CPM) and epithelial cell adhesion molecule (EpCAM) genes and the oxygen consumption rate of mitochondria. Hepatic progenitor cells transplanted into a mouse model induced by thioacetamide (TAA) and cyclophosphamide monohydrate (CTX) settled in the damaged livers and differentiated into functional HLCs.

\section{Methods \\ Cell isolation}

Stem cells were isolated from the amniotic membrane after delivery. The use of fetal membrane was approved by the Institutional Review Board (IRB) of Asan Medical Center (Seoul, Korea; 2015-0303), and informed consent was obtained from participants, women aged 33-39 years. All samples were obtained after a normal gestation period (37-38 weeks).

Briefly, the membranes were transferred into a Petri dish with $0.1 \%$ collagenase IV and cut into small pieces under clean bench conditions using operating scissors. The small 
pieces of tissue were transferred to a MACS C tube (Miltenyi Biotec, Bergisch Gladbach, Germany) and mechanically dissociated with a MACS Dissociator (Miltenyi Biotec). Dissociated cells were centrifuged at $500 \mathrm{x}$ g for 3 min. The supernatant was removed and erythrocytes lysed with a $1 x$ RBC lysis buffer (eBioscience, San Diego, California, USA). Then, the culture medium was added and centrifuged at $800 \mathrm{xg}$ for $3 \mathrm{~min}$. The supernatant was removed, and the pellet resuspended with a culture medium. The cells were plated in $0.1 \%$ gelatin (Sigma Aldrich, MO, USA)-coated culture dishes. Only cell preparations with fibroblast-like morphology were used in further experiments.

\section{Culture for mesenchymal stem cells}

Human umbilical cord matrix-derived stem cells (UCMMSCs) were provided by the Asan Stem Cell Center (Asan Institute for Life Sciences, Seoul, Korea). The cells were obtained from the previously described protocols [23]. Both stem cell types (UCM-MSCs and AM-MSCs) were cultured on $0.1 \%$ gelatin-coated culture dishes with a culture medium. The culture medium was based on DMEM/F12 supplemented with 10\% fetal bovine serum (FBS; Gibco, NY, USA), $10 \mathrm{ng} / \mathrm{ml}$ fibroblast growth factor 2 (FGF2; Peprotech, Rocky Hill, NJ, USA), 1\% NEAA (Gibco), 1\% Penicillin/Streptomycin (GeneDirex). Cells were passaged 1 to $3-5$ every 3 to 4 days using trypsin/ EDTA (Gibco, NY, USA).

\section{Culture for primary human hepatocytes}

Primary human hepatocytes (PHH) were purchased from Thermofisher scientific (HMCPMS; Thermofisher Scientific, MA, USA), and were cultured and maintained according to the supplemented protocol. In brief, the hepatocytes were thawed in Cryopreserved hepatocytes recovery medium (CM7000; Thermofisher Scientific), centrifuged at $100 \times \mathrm{g}$ for $10 \mathrm{~min}$, and seeded at $2 \times 10^{6}$ cells/well on a collagen-coated plate in cryopreserved hepatocyte plating medium (CM9000; Thermofisher Scientific). After incubating the plate at $37^{\circ} \mathrm{C}$ for $6 \mathrm{~h}$, the culture medium was replaced by William's medium (Gibco) supplemented with hepatocytes maintenance supplement pack (CM4000; Thermofisher Scientific).

\section{Quantitative RT-PCR}

Total RNA was extracted using an RNeasy Mini Kit (Qiagen, CA, USA) following the manufacturer's instructions. CDNA was synthesized with an Ultrascript 2.0 cDNA Synthesis Kit (PCR Biosystems, London, UK), and qRT-PCR was performed using a Power SYBR ${ }^{\circ}$ Green PCR Master Mix (Applied Biosystems, CA, USA) on a QuantStudioTM real-time PCR System (Applied Biosystems). RNA levels were normalized with GAPDH. Primer sequences are listed in Table S1.

\section{Flow cytometric analysis}

To measure cell membrane surface proteins, cells were collected after detachment with trypsin/EDTA, and immunostained for $30 \mathrm{~min}$ at $4{ }^{\circ} \mathrm{C}$ with fluorescenceconjugated primary antibodies. The following antibodies were used: PE-CD34, FITC-CD90, FITC-CD105, PEMHC I, APC-MHC II (BD Biosciences Pharmingen, San Diego, CA, USA), and PE-HLA-G (MHC Ib) (Biolegend, CA, USA). After immunostaining, the cells were washed three times with PBS and suspended in $0.2 \mathrm{ml}$ PBS for analysis. The fluorescence of samples was measured using a FACS Calibur (Becton Dickinson and Company, NJ, USA) and analyzed with FlowJo software (ver 10.6.1; Treestar, OR, USA).

\section{Osteogenesis and adipogenesis of AM-MSCs}

Differentiation was performed using Osteogenesis and Adipogenesis differentiation Kit (Thermofisher Scientific) to generate the osteocytes and adipocytes in AM-MSCs. The differentiation protocols were performed according to the kit's recommendations.

\section{Measuring the cell growth rate}

To measure the extent of cell growth rate, stem cells were seeded at $1 \times 10^{5}$ cells in $0.1 \%$ gelatin-coated 6 -well plates at every passage. Cell numbers were counted by hemocytometer. The extent of cell number was calculated as a cell growth rate from the formula: Day 3 cell number/ $1 \times 10^{5}$ cells.

\section{Production of B2M-KO-AM-MSCs}

Human genomic $B 2 M$ sequences were analyzed and selected using the web tool Benchling (https://benchling. $\mathrm{com} /$ ). B2M-specific CRISPR-Cpf1 expression vector was constructed by cloning the annealed oligomers (5' -agatCCGATATTCCTCAGGTACTC-3' and $5^{\prime}$-aaaa GAGTACCTGAGGAATATCGG-3') into a pY108 lentiviral vector (Addgene, plasmid \#84739). Infectious lentiviral particles were produced as described previously and were precipitated using Lenti Concentrator (Origene, Rockville, Maryland, US) according to the manufacturer's protocol [24]. To produce stable B2MKO-AM-MSCs, resuspended lentivirus in culture media were added to AM-MSCs and were incubated for $24 \mathrm{~h}$ in the culture medium. The cell culture medium was replaced with a fresh medium containing $4 \mu \mathrm{g} / \mathrm{ml}$ puromycin and incubation continued for a further $24 \mathrm{~h}$. AM-MSCs in which B2M was knocked out and that did not express MHC I was selected with a BD FACSAria ${ }^{\mathrm{m}}$ III Cell Sorter. B2M-KO was accessed by an Indel sequencing primer (Table S1). 


\section{PBMC proliferation assay}

The proliferation assay was performed in the previous report with simple modification [24]. Briefly, the MSCs $\left(3 \times 10^{4}\right.$ cells/well $)$ were plated onto a 96-well plate in $100 \mu \mathrm{l}$ of MSC culture medium and were allowed to adhere to the plates overnight. The next day, the medium (RPMI 1640 medium supplemented with 10\% FBS, 2 mM L-glutamine, $1 \% \mathrm{P} / \mathrm{S}$ ) was fully changed, and human PBMCs $(n=4)$ were added to wells $\left(1 \times 10^{5}\right.$ cells/well in $100 \mu \mathrm{l}$ volume) in a containing or lacking MSCs with or without $5 \mu \mathrm{g} / \mathrm{ml}$ phytohemagglutinin (PHA, Sigma). Human PBMCs with or without PHA were used as positive or negative controls. After 7 days, $100 \mu$ lof cells from each well was transferred to new 96-well plates with a $10 \mu \mathrm{l}$ CCK-8 assay kit (Dojindo). The absorbance at 450 $\mathrm{nm}$ was measured with a microplate reader.

\section{Transcriptome analysis}

AM-MSCs $(n=3)$ and UCM-MSCs $(n=3)$ were sequenced by strand-specific, paired-end sequencing (Illumina, San Diego, CA, USA), generating approximately 1.1 to $1.3 \times 10^{6}$ reads per sample. The quality of the raw data sets was analyzed with the software FastQC (v0.11.5), and adapter sequences of $<20 \mathrm{bp}$ in length, and sequences with a quality score lower than Q20, were removed using Cutadapt software (v1.5) to increase mapping quality. After trimming, the remaining sequences, constituting 97.3 to $98.8 \%$ of the raw data sets, were aligned with the human reference genome (GRCh38.p13) using STAR software (v2.7.5c), and reads were summarized using featureCount software. Normalization of reads, analysis of gene expression, and calculation of differentially expressed genes was performed using DESeq2 (1.28.1). Gene Ontology Enrichment Analysis of the differentially expressed genes was conducted using online tools (http:// geneontology.org). Functional enrichment in the Biological Process of the GO terms was analyzed. A list of endoderm-associated genes was retrieved from the online human gene database (https://www.genecards.org/).

\section{In vitro hepatic differentiation}

Stem cells were differentiated by the previously published conventional hepatogenic differentiation protocol [9] and an advanced protocol. Briefly, in the advanced protocol, the cells were seeded on $0.1 \%$ gelatin-coated dishes at 7000 cells $/ \mathrm{cm}^{2}$ in a cell culture medium. After 2 days, they were cultured for 7 days with Step- 1 medium consisting of Iscove's Modified Dulbecco's Medium (IMDM; Gibco) supplemented with $0.1 \%$ polyvinyl alcohol (PVA; Sigma Aldrich) or 1\% FBS, $10 \mathrm{mM}$ nicotinamide (Sigma Aldrich), $20 \mathrm{ng} / \mathrm{ml}$ hHGF (Peprotech), $10 \mathrm{ng} / \mathrm{ml} \mathrm{FGF2,} 2 \mu \mathrm{M}$ 5azacytidine (Sigma Aldrich), $0.1 \mu \mathrm{M}$ dexamethasone (Sigma Aldrich), 1\% insulin-transferrin-selenium (ITS; Gibco), 3 нM CHIR99021, 20 ng/ml EGF (Peprotech), and
$10 \mu \mathrm{M}$ Fasudil (AdooQ Bioscience, Irvine, CA, USA). For hepatic maturation, the Step-1 medium was replaced with Step-2 medium consisting of IMDM supplemented with $1 \mu \mathrm{M}$ dexamethasone, $1 \%$ ITS, $20 \mathrm{ng} / \mathrm{ml}$ Oncostatin $\mathrm{M}$ (OSM, Peprotech), 20 ng/ml hHGF, and $10 \mathrm{uM}$ Fasudil.

\section{Immunocytochemical staining}

Cells were fixed with $4 \%$ formaldehyde overnight, washed with the PBST buffer, permeabilized in $0.5 \%$ Triton X-100 and blocked in PBST containing $1 \%$ bovine serum albumin (Sigma Aldrich). Samples were incubated with primary antibodies, anti-human Albumin, anti-human CYP3A4 (1:100; Santa Cruz Biotechnology, Dallas, TX, USA) and anti-human EpCAM (1:100; Abcam, Cambridge, MA, USA), overnight at $4{ }^{\circ} \mathrm{C}$, followed by goat anti-mouse IgG Alexa Fluor 488-conjugated and donkey anti-rabbit IgG Alexa Fluor 647-conjugated secondary antibody (1:500; Abcam). Nuclei were counterstained with 4', 6-diamidino-2-phenylindole (DAPI) (Sigma Aldrich) for $10 \mathrm{~min}$, and fluorescence signals were detected using an AxioObserver Z1 microscope (Carl Zeiss, Oberkochen, Germany).

\section{Detection of secreted human albumin}

The presence of human albumin was determined by the Human albumin ELISA Kit (Bethyl Laboratories, Texas, USA). The assay procedure was performed according to the supplier's recommendation. The albumin secretion was normalized to culture day and total cell numbers.

\section{Measurement of CYP3A4 activity in vitro}

To assess the hepatic enzyme activity, $25 \mu \mathrm{M}$ rifampicin (Sigma), which is a CYP3A4 inducer, was treated for $48 \mathrm{~h}$ in cells. Next, $20 \mu \mathrm{M}$ midazolam (Sigma), previously reported as the substrate of CYP3A4 [25], was treated for $24 \mathrm{~h}$. Sample preparation involved simple protein precipitation with organic solvent (cold acetonitrile). Briefly, cell samples $(50 \mathrm{uL})$ were precipitated with $150 \mu \mathrm{L}$ of cold acetonitrile containing internal standard carbamazepine $(\mathrm{CBZ}, 10 \mathrm{ng} / \mathrm{mL})$, and agitating with a vortex mixer before centrifugation. Samples were centrifuged at $3400 \mathrm{rpm}$, $4{ }^{\circ} \mathrm{C}$ for $20 \mathrm{~min}$ and the supernatant samples were analyzed by LC-MS/MS according to the previous publication [26].

Briefly, the LC-ESI/MS/MS system consisted of an Agilent 1200 series HPLC system (Agilent Technologies, Wilmington, DE, USA) coupled with an API 4000 LCMS/MS with a Turbo V IonSpray source (Applied Biosystems, Foster City, CA, USA) operated in the positive ion mode. The chromatographic column was conducted on an Atlantis dC18 column $(50 \times 2.1 \mathrm{~mm}$ i.d., $3 \mu \mathrm{m}$, Waters, Milford, MA, USA) with a SecurityGuard C18 guard column $(2.0 \times 4.0 \mathrm{~mm}$ i.d., Phenomenex, Torrance, CA, USA). The sample injection volume was $5 \mu \mathrm{L}$, and the 
flow rate was set at $0.4 \mathrm{~mL} / \mathrm{min}$, and the oven temperature was maintained at $30^{\circ} \mathrm{C}$. The mobile phase consisted of HPLC water (A) and acetonitrile (B), each containing $0.1 \%$ formic acid. The TurbolonSpray interface was operated in the positive ion mode at $5500 \mathrm{~V}$. The operating conditions were determined as follows: ion source temperature, $600^{\circ} \mathrm{C}$; nebulizing gas flow, $50 \mathrm{~L} / \mathrm{min}$; auxiliary gas flow, $5.0 \mathrm{~L} / \mathrm{min}$; curtain gas flow, $20 \mathrm{~L} / \mathrm{min}$; and collision gas (nitrogen) pressure $3.4 \times 10^{-5}$ Torr. Nitrogen gas was used for the curtain gas (CUR), collision gas (CAD), and nebulizer gas (NEB). The detection was conducted using multiple reaction monitoring (MRM) of the transitions of $\mathrm{m} / \mathrm{z} 342>324$ for 1-hydroxymidazolam and m/z $237>194$ for carbamazepine (internal standard). Acquisition and analysis of data were performed using Analyst software (ver. 1.5.2, Applied Biosystems, Foster City, CA, USA).

The enzyme activity was also determined using the P450-Glo CYP3A4 kit (Promega, USA). The experiment was performed according to the supplier's recommendations. The luminescence was measured by SpectraMax ${ }^{\circ} \mathrm{L}$ Luminometer (Molecular Devices, CA, USA). The activity was normalized to the culture day and dsDNA content of each sample.

\section{Seahorse assay}

To measure oxygen consumption rates (OCR) in differentiated cells, stem cells were seeded at 7000 cells $/ \mathrm{cm}^{2}$ and differentiated into hepatocyte-like cells (HLCs) to day $0,7,10,12$, and 14 in $0.1 \%$ gelatin-coated $\mathrm{XFe} 24$ cell culture plates (Agilent Technologies, Santa Clara, CA, USA). Mitochondrial OCR was measured with an XF Cell MitoStress test kit in an XF24 extracellular flux analyzer (Agilent Technologies) and calculated as described [9]. Values were normalized by the amount of cellular DNA.

\section{Transplantation experiments}

To establish an acute liver failure model, eight-week-old male C57BL/6 or NOD. Cg-Prkdc ${ }^{\text {scid }} \mathrm{Il} 2 \mathrm{rg}^{\mathrm{tm} 1 \mathrm{Wjl}} / \mathrm{SzJ}$ (NSG) mice were injected intraperitoneally with $0.08 \mathrm{mg} / \mathrm{g}$ thioacetamide (TAA; 163,678, Sigma Aldrich) or an additional $0.025 \mathrm{mg} / \mathrm{g}$ cyclophosphamide monohydrate (CTX; C0768, Sigma Aldrich) after 24h. Next, the cells with various stages were transplanted via the intrasplenic route $\left(5 \times 10^{5}\right.$ cells per mouse) of NSG. All mice were purchased from JOONG AH BIO (Suwon, Korea). The mouse study was approved by the Asan Institutional Animal Care and Use Committee (IACUC, 2018-12-167, 2019-12-062, and 2020-02-208).

\section{Blood analysis}

Complete blood counts $(\mathrm{CBC})$ and analyses of peripheral blood from mice were performed using an $A B C-V E T$ (Scilvet, Germany) and FUJI DRI-CHEM clinical chemistry analyzer (FUJI, Japan), respectively, at AniCom Medical Center (Seoul, Korea).

\section{Histological staining and analysis}

The retrieved liver tissues were fixed in $3.7 \%$ formaldehyde and embedded in paraffin. The paraffin blocks were sectioned at $4 \mu \mathrm{m}$-thick. To assess acute liver failure in chemically treated mice, the paraffin sections were stained with hematoxylin and eosin (H\&E) and scored by Suzuki's method [27]. Three weeks after transplantation, liver repopulation and regeneration were assessed by $\mathrm{H} \& \mathrm{E}$ staining, and immunohistochemistry (IHC). Human albumin was stained with DAB substrate using the previously described IHC methods [9]. Histological images were obtained by light microscopy using an Olympus DP27 (Olympus, Melville, NY, USA).

\section{Immunofluorescence staining}

Transplanted liver tissues were fixed in 3.7\% formaldehyde overnight at $4{ }^{\circ} \mathrm{C}$, incubated overnight at $4{ }^{\circ} \mathrm{C}$ in $30 \%$ sucrose, overlaid with OCT compound, and frozen in liquid nitrogen. The frozen blocks were sectioned with a cryotome of $10 \mu \mathrm{m}$ thickness. The sections were permeabilized with $0.2 \%$ Triton X-100/PBS for $30 \mathrm{~min}$ at RT, blocked with $10 \%$ FBS buffer at RT in a humidity chamber, and stained overnight with anti-human albumin diluted 1:100 at $4{ }^{\circ} \mathrm{C}$ in the humidity chamber. The secondary antibody was goat anti-mouse IgG H\&L Alexa Fluor ${ }^{\circ}$ 647; Abcam, 1:100). Nuclei were counterstained with 4', 6-diamidino2-phenylindole (DAPI) for $10 \mathrm{~min}$, and fluorescence signals were detected using an AxioObserver Z1 microscope.

\section{Human mitochondrial DNA detection}

Total DNA was isolated with a PicoPure ${ }^{\mathrm{Tm}}$ DNA extraction kit (Thermofisher Scientific). The PCR reaction was conducted using 2x PCRBIO HS Taq Mix Red (PCRbiosystems) with $300 \mathrm{ng}$ of DNA in a total volume of $20 \mu \mathrm{l}$. The reaction was performed as described in the kit with annealing at $56^{\circ} \mathrm{C}$ for $20 \mathrm{~s}$. Sanger sequencing of the PCR products of injected cells and transplanted cells was carried out by Macrogen (Seoul, Korea).

\section{Evaluation of transplant efficiency}

To determine the percentage of engrafted human cells in the mouse liver, each standard curve of human or mouse mtDNA was prepared by quantitative real-time PCR (qPCR). For preparing the standard curve, both DNA concentrations were measured by NanoDrop ${ }^{\text {tw }}$ 2000/2000c Spectrophotometer (Thermofisher Scientific), and samples with OD 260/280 between 1.8-2.0 were used for further analysis. The DNA concentration was diluted by DNasefree water to the following concentration, 1000, 100, 10, and $1 \mathrm{ng} / \mathrm{ul}$. The qPCR was performed using $1 \mathrm{ul}$ of the diluted DNA (1000, 100, 10, and $1 \mathrm{ng}$ ) and Power SYBR ${ }^{\circ}$ 
Green PCR Master Mix on a QuantStudio ${ }^{\text {ma }}$ real-time PCR System. After finishing the qPCR, the standard curve of human or mouse mtDNA was made using the diluted DNA concentration (X-axis) and $\mathrm{CT}$ value ( $\mathrm{Y}$-axis) (Fig. S3e). Finally, human and mouse mtDNA concentrations were acquired through the standard curve in transplanted samples, and the percentage of transplantation efficiency was calculated following formula: [human mtDNA / (mouse mtDNA + human mtDNA)] $\times 100(\%)$.

\section{Statistical analysis}

All experiments were performed on at least three $(n=3)$ independent biological samples, and data are presented as means \pm standard deviations (SD). Statistical analysis was performed using GraphPad Prism 6.0 software (GraphPad Software, CA, USA). Comparisons of three or more data sets were performed by one-way or two-way ANOVA followed by Bonferroni's multiple comparison tests. Twogroup comparisons were made using two-tailed Student's t-tests. $P<0.05$ was considered statistically significant.

\section{Results}

Characterization of amniotic membrane-derived mesenchymal stem cells

Three amniotic membrane-derived mesenchymal stem cells (AM-MSCs) were compared with umbilical cord matrix-derived mesenchymal stem cells (UCM-MSCs). Morphologically, AM-MSCs were fibroblast-like shapes with ovoid nuclei, which is similar to UCM-MSCs (Fig. 1a). However, the AM-MSCs were relatively smaller in size and granularity than UCM-MSCs by measuring flowcytometry [28] (Fig. 1b). Like UCM-MSCs, AMMSCs expressed the mesenchymal stem cell (MSC) surface markers, CD90, and CD105, but did not express CD34 (Fig. 1c). The major histocompatibility complex (MHC) profile of the AM-MSCs was similar to that of the UCM-MSCs; positive for MHC I and negative for MHC II (Fig. 1d). To eliminate contamination of the amnion derived-epithelial cells, which could be expressed in non-canonical HLA types (MHC Ib), such as HLA-G [29], we observed HLA-G expression in AMMSCs resulting in negative in all three AM-MSC lines (Fig. 1e). a

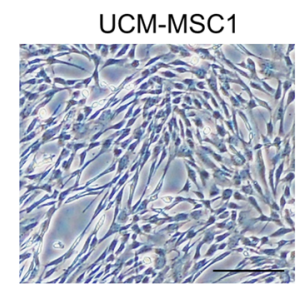

C

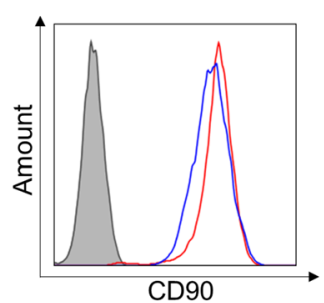

e

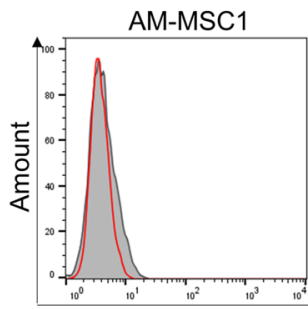

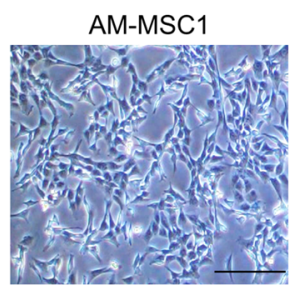
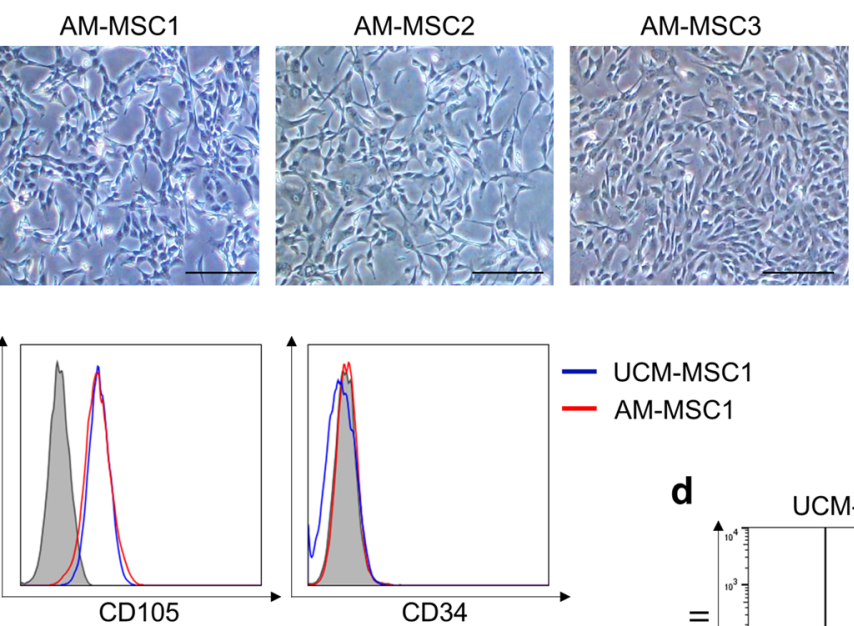

- UCM-MSC1

- AM-MSC1 b

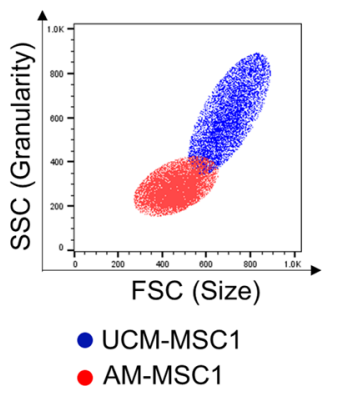

d

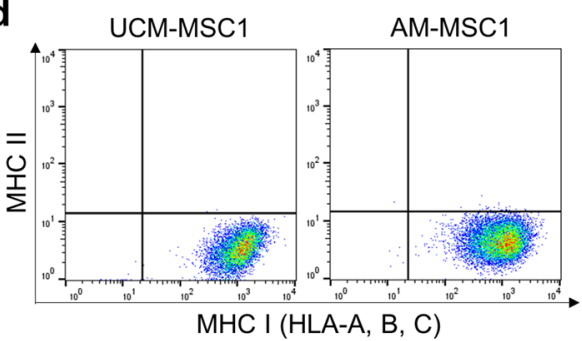

Fig. 1 Phenotypes of AM-MSCs. a Morphology of stem cells isolated from the amniotic membrane and umbilical cord matrix. Scale bar $=200 \mu m$. b The FSC-SSC dot plot of AM-MSCS, and UCM-MSCS. FSC represents cell size, and SSC represents the granularity of cells in flow cytometry (Red dot: AM-MSC1, Blue dot: UCM-MSCS). c Flow cytometry analysis shows that AM-MSC1 and UCM-MSC1 had similar characteristics in terms of expression of MSC surface markers (CD90 and CD105) and absence of a hematopoietic stem cell marker (CD34). d Profile of MHC class I (HLA-A, $B, C)$ and II in AM-MSC1 and UCM-MSC1. e Profile of non-canonical MHC class Ib (HLA-G) in three AM-MSCs cell lines 
Next, we compared the global transcriptomes of each 3 AM-MSC and UCM-MSC lines derived from different individuals. A total of 3957 genes were differentially expressed between the two stem cell groups (Fig. 2a). Because AM-MSCs and UCM-MSCs were different origins, they had different gene profiles (Fig. 2b). Among them, 2100 genes were significantly more highly expressed in AM-MSCs and 1857 genes were more highly expressed in UCM-MSCs (Fig. 2c). We also performed GO-term enrichment analysis to classify the genes with similar genetic functions in the biological process. The result showed that the genes differentially expressed between the two types of stem cells fell into several different biological categories, such as biological regulation, metabolic process, response to stimulus, signaling, development process, immune system process, proliferation, reproductive process, and growth (Fig. 2d).

In quantitative PCR for gene expression, it showed that AM-MSCs expressed higher levels of representative stem cell makers, octamer-binding transcription factor 4 (OCT4), NANOG, and sex-determining region Y-box 2 (SOX2) (Fig. 2e, $P<0.01$ ). These results suggested that AM-MSCs had more stemness potential and were promising for further research [30]. In terms of inflammationrelated genes, expression of $I L-1 \beta$ was significantly lower, while that of tumor necrosis factor-alpha (TNF$\alpha), I L-6$, transforming growth factor-beta $(T G F \beta)$, and $I L-10$ was higher in all three AM-MSC preparations than in the UCM-MSCs (Fig. 2f, $P<0.01$ ). IL- $1 \beta$ is a proinflammatory cytokine involved in the acute inflammatory response and graft death after transplantation [31]. The lower levels of expression of $I L-1 \beta$ and higher levels of TGF- $\beta$ and $I L-10$, which are known as antiinflammatory cytokines, could reduce inflammatory responses when AM-MSCs are transplanted into patients.

In summary, AM-MSCs and UCM-MSCs are similar in morphology and expression of surface markers but differ in size and gene expression.

\section{The mass-production potential of AM-MSCs}

For applications as cell-based therapies, large-scale expansion of stem cells is required. To test the mass-production potential of AM-MSCs, we counted the number of stem cells isolated per $\mathrm{cm}^{2}$ of the amniotic membrane (Fig. 3a). In three independent experiments, the average number of AM-MSCs has harvested $2 \times 10^{6}$ cells per $\mathrm{cm}^{2}$. These stem cells were grown at least 8 -fold at every passage up to 10-passage (Fig. 3b).

To confirm that AM-MSCs maintain their characteristics until passage 10, first, we measured the mRNA expression of pluripotent markers [32], OCT4, NANOG, and $S O X 2$, in every other passage. All three genes were expressed at similar levels among passages (Fig. 3c). Second, we measured the MSC CD marker's expressions and compared passages 2 and 10 resulting in similar patterns (Fig. 3d). More than 95\% of CD90 and CD105 were expressed while CD34 was not expressed in both passages. Finally, we examined the mesenchymal lineage differentiation ability and conducted osteogenic and adipogenic differentiation using passages 2 and 10 of AMMSCs. Both passages were highly expressed than undifferentiated AM-MSCs in terms of the osteogenic markers; $A L P$ and $O C N$ and adipogenic markers; PPARY and FABP4 $(P<0.001$, Fig. 3e). Between 2 passages, the levels were comparable, suggesting that AM-MSCs maintained their differentiation ability at passage 10 .

In conclusion, since the stem cells have shown a growth more than 5 times per passage up to passage 10 while maintaining stemness, more than $10^{13}$ cells could be obtained from a donor individual (Fig. 3f). Given that a maximum of $2 \times 10^{8}$ cells is used per person in clinical trials of transplantation [33], this yield would be sufficient to treat more than 10,000 individuals.

\section{Generation of universal cells from AM-MSCs}

We also induced B2M-knocking out on AM-MSCs to show potential as universal donors. To generate B2MKO-MSCs, we targeted the $B 2 M$ gene, which up-regulates MHC I, using the CRISPR-Cpf1 system (Fig. 4a) [34]. Stem cells, including AM-MSCs, are MHC I positive, and so can cause immune rejection in transplanted recipients. After inducing B2M-knockout (KO), MHC I-negative cells were sorted by flow cytometry. As we expected, the expression of MHC I was declined, and the B2M gene was successfully knockout (Fig. 4b and c). The KO-AM-MSCs have measured the expression of MSC CD markers. The CD90 and CD105 expressed positively while CD34 was negative (Fig. 4d), but the growth rate was decreased in the B2M-KO (Fig. 4f). However, interestingly, CD47 expression was up-regulated than intact AM-MSCs (Fig. $4 \mathrm{e})$. The CD47 protects transplanted cells from macrophage phagocytosis. This is because when CD47 expression is low, macrophages can recognize the transplanted cells as non-self, known as the do not eat me signal [35]. Finally, we evaluated the immune response of B2M-KOAM-MSCs with human PBMCs using a proliferation assay. The B2M-KO-AM-MSCs were comparable proliferation with negative control while significantly lower than intact AM-MSCs $(P<0.05$, Fig. $4 g)$ suggesting less immune response.

In vitro differentiation of AM-MSCs into hepatic progenitors In our previous study of hepatic differentiation, MSCs were differentiated into hepatocyte-like cells (HLCs) using specific growth factors or chemicals such as hHGF, FGF2, and 5-azacytidine (5-aza), Fasudil [9]. We attempted to differentiate AM-MSCs into hepatic progenitor cells (HPCs) using the previous conventional protocol (Fig. 5a). 


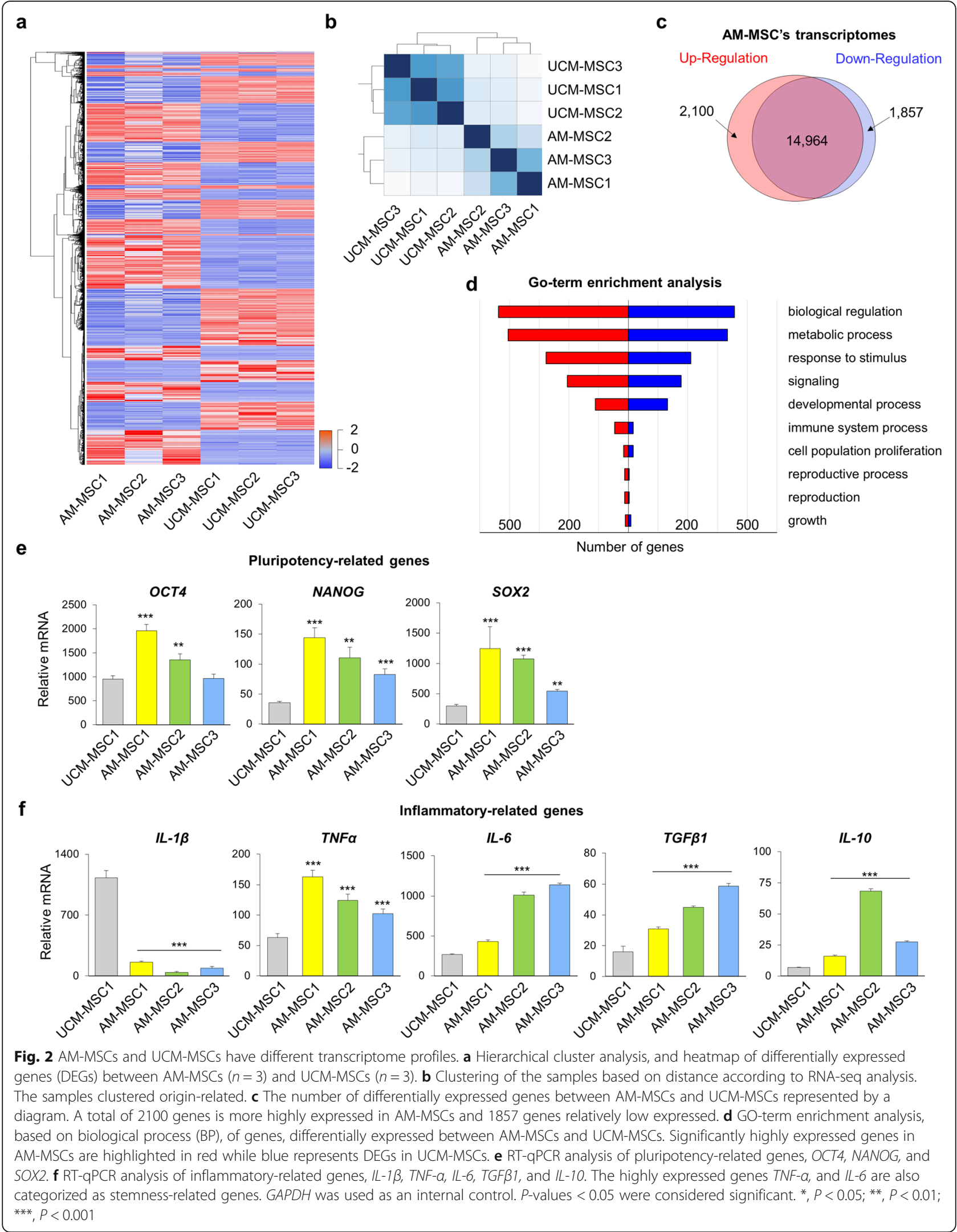


a
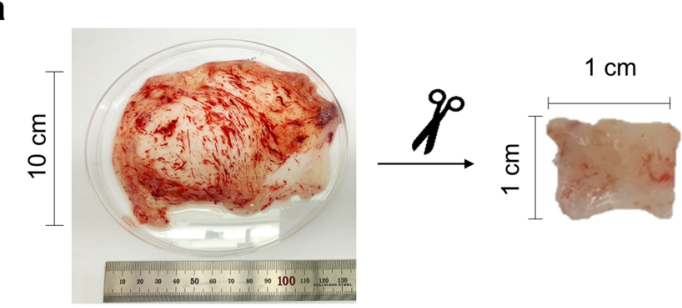

Extraction

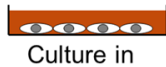
culture media for 10 days

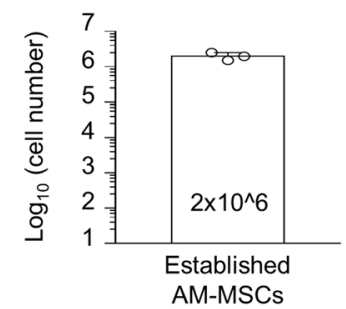

b

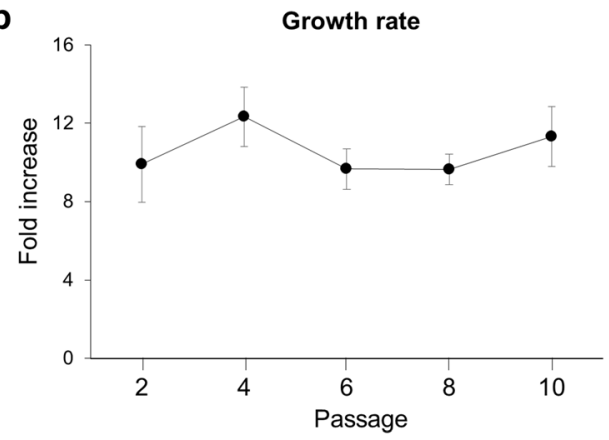

d

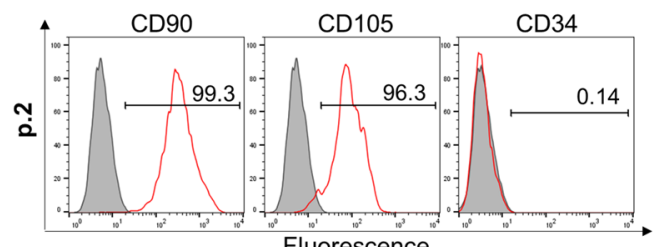

Fluorescence

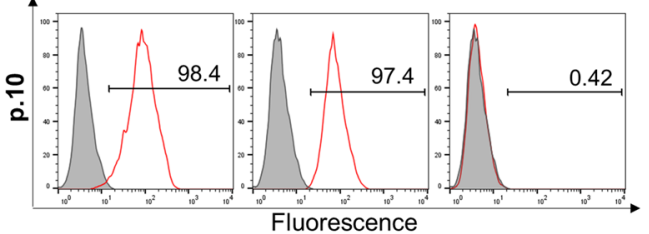

f

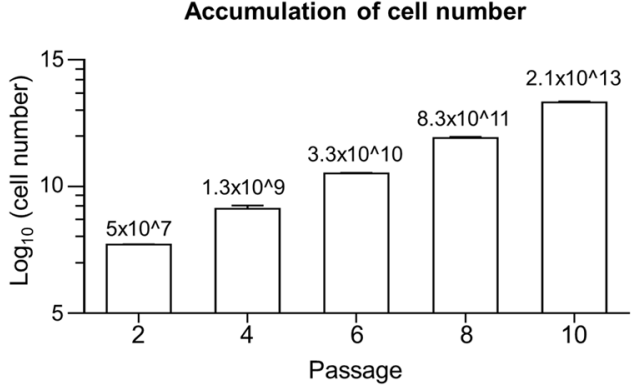

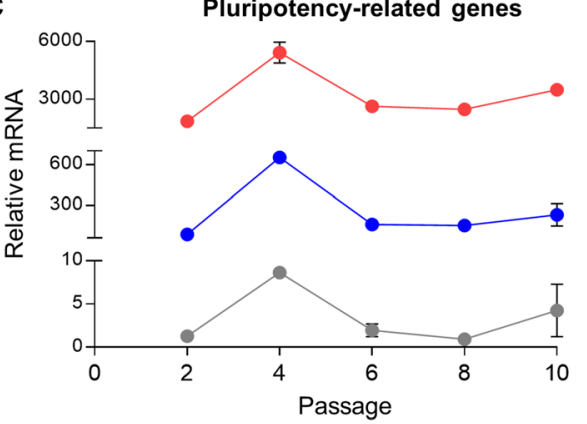

e

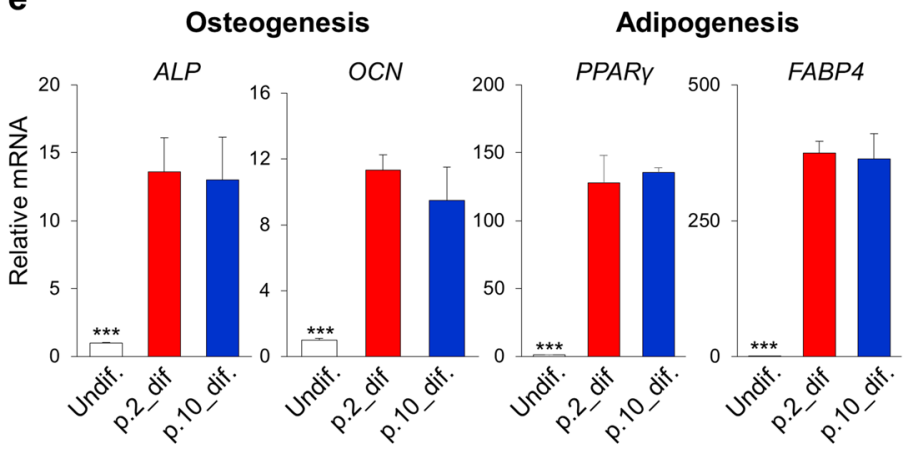

Fig. 3 Mass production of AM-MSCs. a The isolation procedure, and the number of established AM-MSCs per $\mathrm{cm}^{2}$ of the amniotic membrane. Yaxis values represent the logarithm of total cell numbers. $\mathbf{b}$ Growth rate of AM-MSCs based on passages (Biological replication, $n=3$ ). $\mathbf{c}$ mRNA levels of pluripotency-related genes OCT4, SOX2, and NANOG according to the passage number. GAPDH was used as an internal control for RTqPCR (Technical replication, $n=3$ ). d Expression percentage of MSC markers (CD90, CD105) and hematopoietic markers (CD34) in early (p.2) and late (p.10) passage of AM-MSCs. e mRNA expression analysis of osteogenesis-related (ALP, OCN) and adipogenesis-related (PPARY, FABP4) genes on day 14 after the induction of differentiation (Biological replication, $n=3$ ). GAPDH was used as an internal control. P-values $<0.05$ were considered significant. ${ }^{* *} P<0.001$. undif, undifferentiated cells; dif, differentiated cells. $\mathbf{f}$ Estimation of total cell numbers during the passage. More than $2 \times$ $10^{13}$ AM-MSCs could be harvested after ten passages. If maximally, the $2 \times 10^{8}$ cells are used to transplant into a patient, it can be used in more than 10,000 people. $Y$-axis values represent the logarithm of total cell numbers 
a c

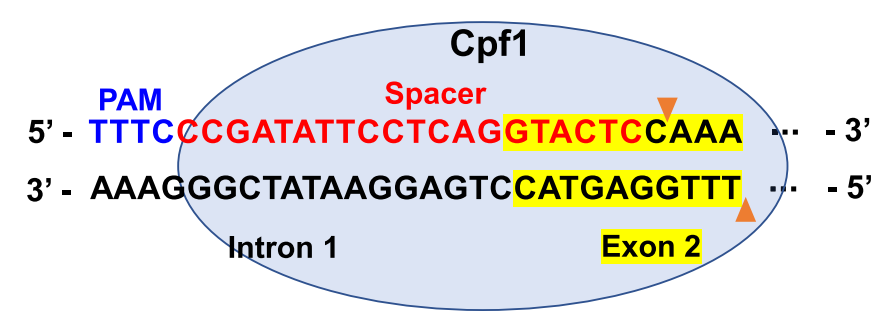

C

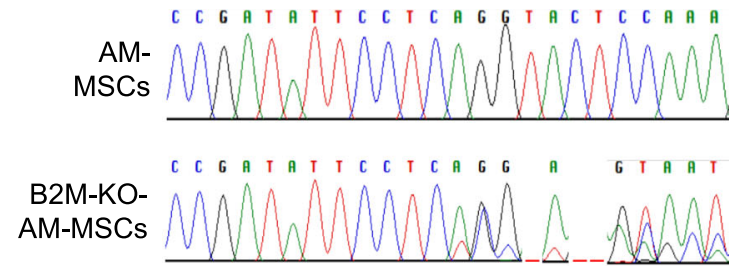

b
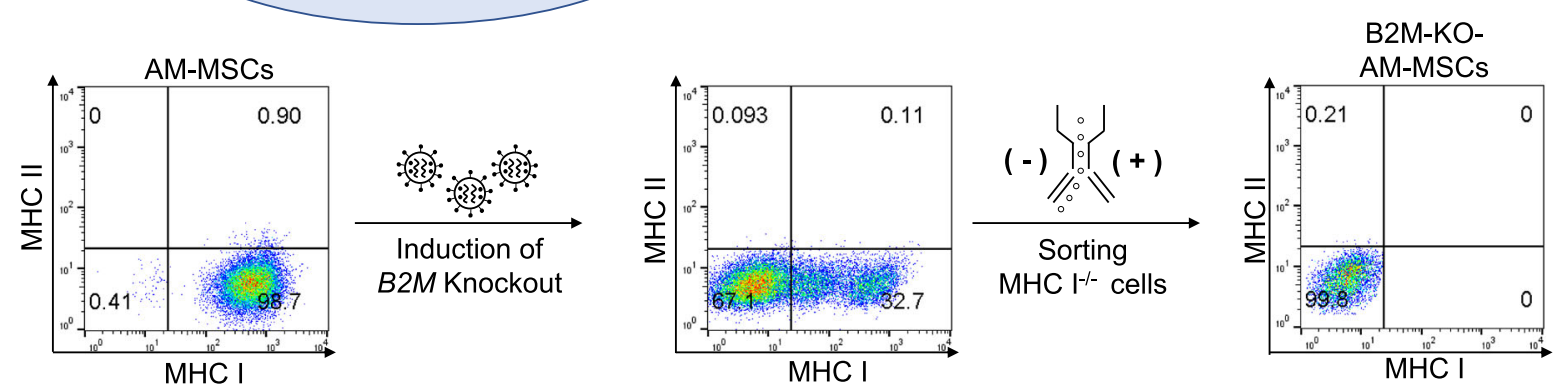

d
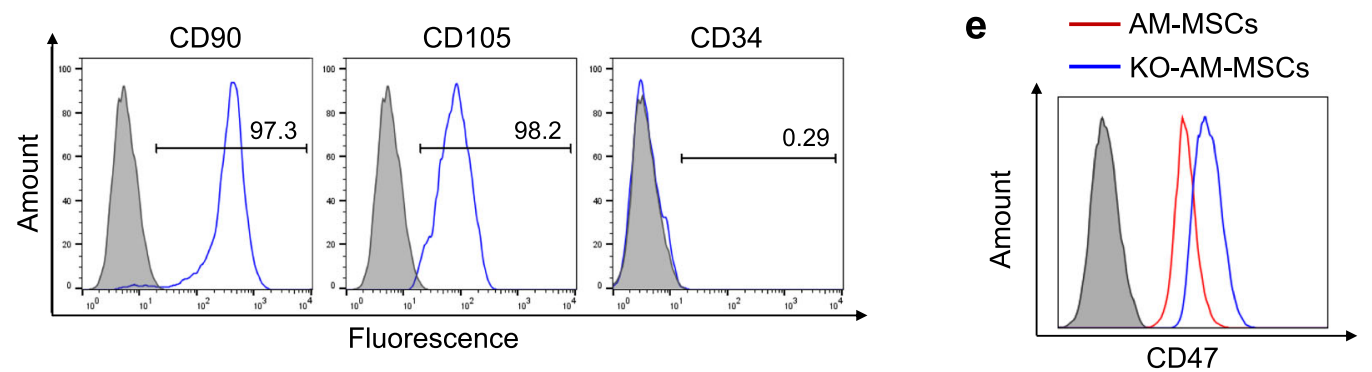

f

Fluorescence

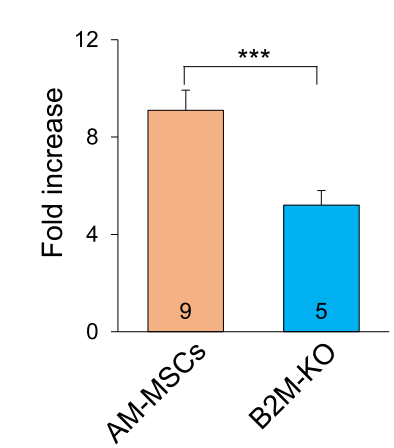

g PBMC proliferation

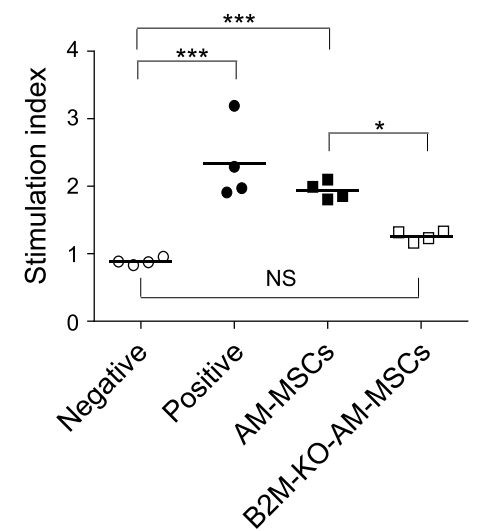

Fig. 4 Generation of hypo-immune potential universal cells from AM-MSCs. a The target DNA sequence in the human B2M locus is shown in red. b Schema of the process for generating universal donor AM-MSCs. After inducing B2M knockout, MHC I-negative AM-MSCs are selected by flow cytometry. c Sequencing of B2M in MHC I-KO and AM-MSCs after B2M knockout in AM-MSCs. d Expression of MSC CD markers (CD90, CD105) and hematopoietic markers (CD34) in B2M KO-AM-MSCs. e CD47 expression levels in AM-MSCs and B2M-KO AM-MSCs analyzed by flow cytometry. f Growth rate of AM-MSCs and B2M-KO-AM-MSCs. B2M-KO: B2M-KO-AM-MSCs. $\mathbf{g}$ The evaluation of PBMC proliferation assays (4 donors of PBMCS). All control groups were only cultured in a medium without MSC. Negative control: PBMC cultured without PHA, Positive control: PBMC cultured with PHA. NS: no significant, $P$-values $<0.05$ were considered significant; ${ }^{*}, P<0.05 ;{ }^{* *}, P<0.01 ;{ }^{* * *}, P<0.001$

The morphological change from an oval or polygonal-like structure was observed (Fig. 5b). However, human albumin (ALB) was significantly lower in AM-MSCs-derived HPCs (AM-HPCs) compared to UCM-MSCs-derived HPCs (Fig. 5c).
To establish an efficient method of hepatic differentiation, we compared gene expression related to the endodermal lineage in AM-MSCs and UCM-MSCs in the previous RNA sequencing data (Fig. 5d). A total of 3317 endoderm- 
a

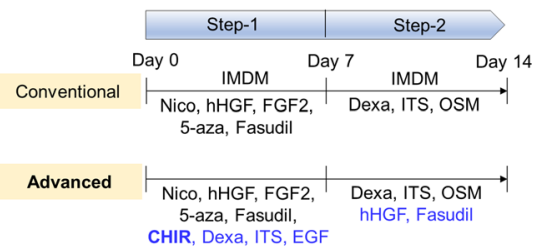

c

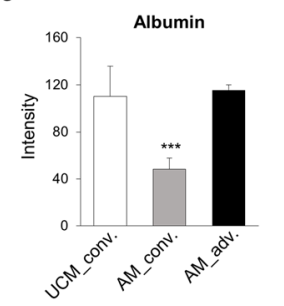

e

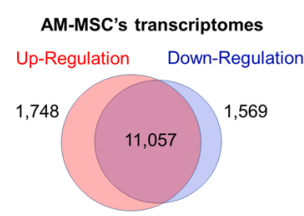

h

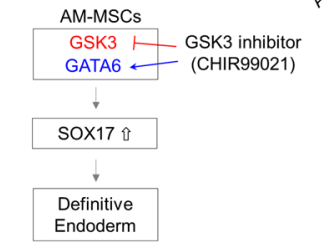

k

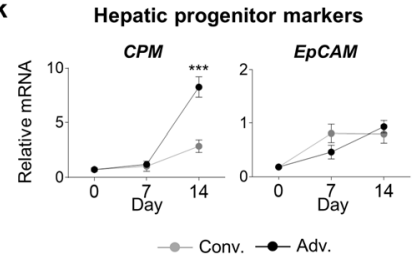

। d Endoderm-related genes
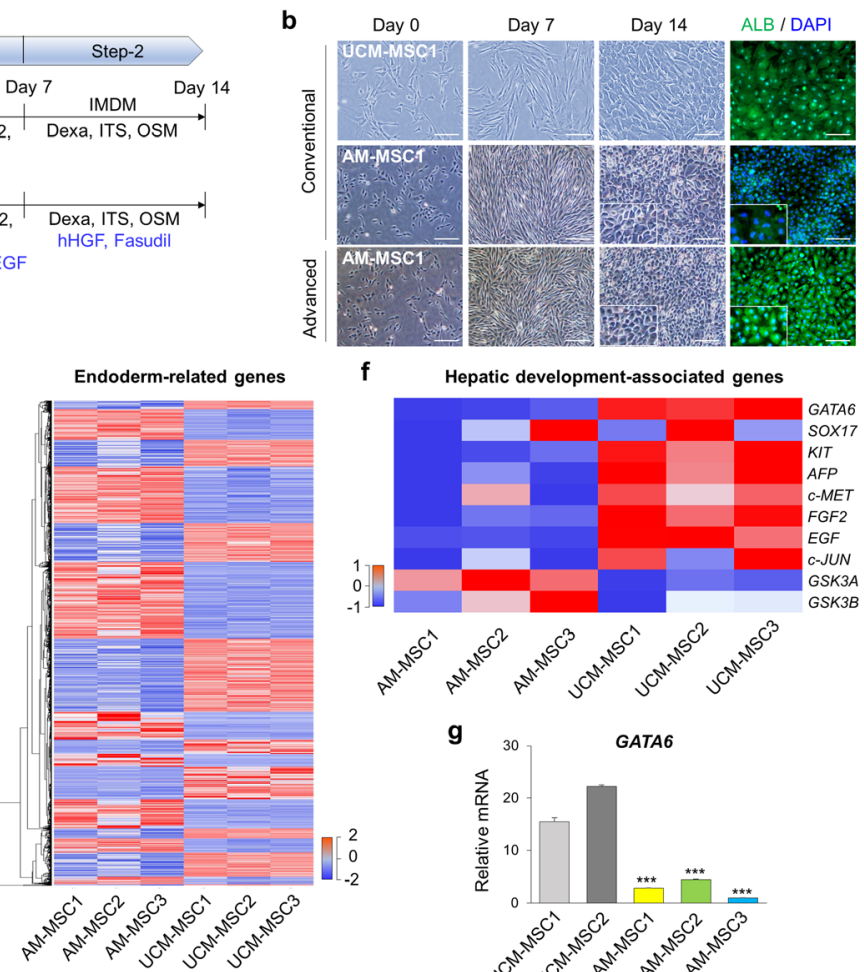

f

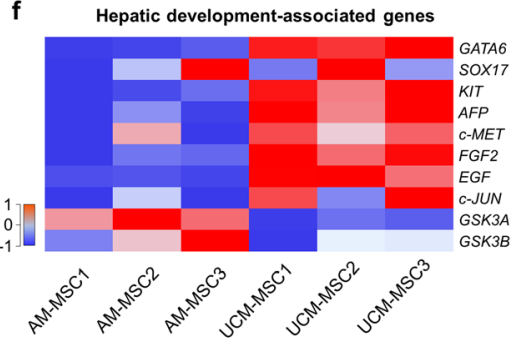

g $30 \quad$ GATA6
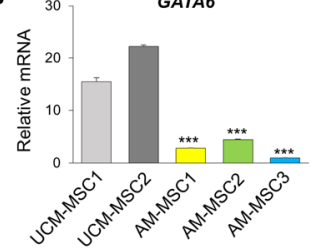

GATA6 SOX17
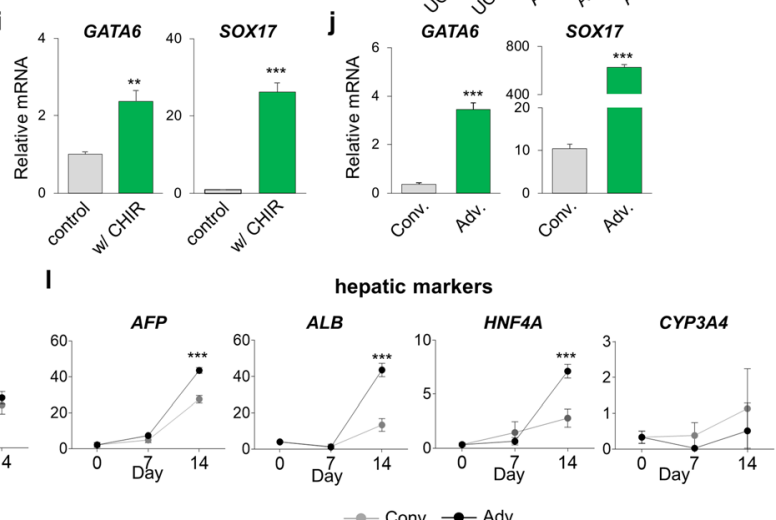

Fig. 5 An efficient protocol for enhancing the hepatic differentiation potential of AM-MSCs. a The conventional and advanced in vitro hepatic differentiation protocols. The advanced protocol was modified from the conventional protocol by adding several chemicals highlighted in blue. OSM: Oncostatin M. b Morphology of cells during hepatic differentiation and ALB expression on day 14. Green, ALB; Blue, DAPI. Scale bar = 200 mm. c Fluorescence intensity of detected albumin in (b). d Hierarchical cluster analysis, and heatmap of endoderm-related transcriptomes in AM-MSCs $(n=3)$ and UCM-MSCs $(n=3)$. e Numbers of endoderm-related genes differentially expressed between AM-MSCS and UCM-MSCs. $\mathbf{f}$ Heat map of hepatic development-associated gene expression in AM-MSCs $(n=3)$ and UCM-MSCs $(n=3)$. $\mathbf{g}$ RT-qPCR analysis of GATA6 in AMMSCs and UCM-MSCs. $\mathbf{h}$ Scheme of the effect of GSK3 inhibitor (CHIR99021) on AM-MSCs. i Regulation of GATA6, and SOX17 in AM-MSCs in the presence of CHIR99021. $\mathbf{j}$ Effect of the different protocol on the regulation of GATA6 and SOX17 in AM-MSCs. $\mathbf{k}$ RT-qPCR analysis of selected hepatic progenitor markers. I Expression of early hepatic (AFP) and hepatic maturation (ALB, and HNF4A) markers. GAPDH was used as an internal control for RT-qPCR. Two-way analysis of variance (ANOVA) was performed on the data for differentiation days 0,7 , and 14 points. $P$-values $<0.05$ were considered significant. ${ }^{* *} P<0.001$. Conv. Conventional protocol; Adv. Advanced protocol

related genes were differentially expressed between the two stem cell types: 1748 were more highly expressed in AMMSCs, and 1569 in UCM-MSCs (Fig. 5e). We also analyzed the transcription profiles of hepatic development-associated genes (Fig. $5 \mathrm{f}$ and Table S2). It showed that GATA6, KIT, $A F P$, c-MET, FGF2, EGF, and c-JUN were down-regulated and GSK3A was up-regulated in AM-MSCs $(P<0.05)$. The high levels of GSK3 could repress the induction of definitive endoderm [36]. Transcriptome analysis of AMMSC and UCM-MSC lines by quantitative PCR confirmed that expression of GATA6 was much lower in all three AM-MSC lines than in UCM-MSCs $(P<0.001$, Fig. 5g). 
CHIR99021 (CHIR), also known as GSK3 inhibitor, could induce GATA6 expression for hepatic differentiation from human embryonic stem cells [37]. Also, downregulated GSK3 could induce upregulation of GATA6 in cancer cells [38]. Therefore, we hypothesized that inhibition of GSK3 could increase the expression of GATA6 (Fig. 5h). CHIR was treated for 2 days and measured the expression of GATA6, and SOX17, which is known as the definitive endodermal marker. As we expected, these two genes showed significantly increased expression in the $\mathrm{w} /$ CHIR group than control $(P<0.01$, Fig. $5 \mathrm{i})$.

Next, we investigated the effect of adding various factors along with CHIR to increase the expression of GATA6 and SOX17. Epidermal growth factor (EGF) and dexamethasone (Dexa) play an important role in hepatic biology and maturation [39]. Insulin-transferrin-selenite (ITS) and fasudil also enhance the stability of stem cell cultures and their differentiation [40]. Based on these factors, we modified the conventional to the advanced protocol by adding CHIR, Dexa, ITS, and EGF. In response, the expression of GATA6 and SOX17 was significantly increased on day $2(P<0.001$, Fig. 5j). Therefore, we efficiently and successfully induced definitive endoderm for hepatic differentiation. We also added hHGF and fasudil in step 2 (Fig. 5a). Finally, we observed cell morphology and stained it for ALB expression. The oval or polygonallike structure of the cells was similar, but ALB was more highly expressed on day 14 (Fig. 5b and c). These findings indicate that the GSK3 inhibitor, CHIR, is essential to induce hepatic differentiation of AM-MSCs through the GATA6 signaling pathway.

We also analyzed the kinetics of gene expressions during HPC differentiation. The expression of CPM increased significantly on day 14 in the advanced protocol, while the expression of $E p C A M$ was similarly expressed $(P<0.001$, Fig. 5k). Alpha-fetoprotein $(A F P)$, as early hepatic marker, $A L B$ and hepatocyte nuclear factor 4 alpha (HNF4A), as markers of hepatic maturation, were more highly expressed on day 14 in the advanced protocol $(P<0.001$, Fig. $5 \mathrm{l})$, while the expression of cytochrome P450 3A4 (CYP3A4) was comparable.

\section{The use of PVA for inducing hepatic differentiation}

FBS is still widely used for inducing hepatic differentiation [41]. However, it causes an acute immune response after transplantation because of xeno-contamination. Therefore, we substituted $0.1 \%$ PVA for $1 \%$ FBS in the advanced protocol (Fig. 6a). The phenotype of differentiated cells was similar when both PVA and FBS were used (Fig. 6b). First, we analyzed the dynamics of gene expressions associated with hepatocyte-related genes on days 7 and 14 using previous reports [42, 43], and compared them with primary human hepatocytes $(\mathrm{PHH})$ control. $C P M$ and $E p C A M$, which are related to hepatic progenitor markers, were expressed more highly in the PVA group on day 14 $(P<0.01$, Fig. 6c). We also analyzed the genes, which are associated with liver-specific plasma and nuclear protein such as $A F P, A L B, H N F 1 A$, and HNF4A. The levels of expression of AFP, ALB, HNF1A, and HNF4A also were higher in the PVA group on day $14(P<0.01$, Fig. $6 \mathrm{~d})$. Moreover, CYP1A2, CYP3A4, UGT1A6, MRP2, and $A S G R 1$, which are related to liver-specific metabolism, were expressed higher in the PVA group on day $14(P<$ 0.05, Fig. 6e). Compared with primary hepatocytes, $\mathrm{PHH}$ was a significantly lower expression of $C P M, E p C A M$, and AFP $(P<0.05)$, while HNF1A and UGT1A6 were comparable. The other genes were higher than on day 14 of the PVA group $(P<0.05)$.

Moreover, we applied the PVA-advanced protocol to UCM-MSCs. The efficiency of hepatic differentiation was significantly increased than the conventional one (Fig. S1a). We also reanalyzed and compared the previously published data [9], the AM-HPCs were more similar to $\mathrm{PHH}$ than those derived from either UCM-MSCs or LDSCs (Fig. S1b).

Next, we examined the protein expression of ALB, EpCAM, and CYP3A4 to evaluate differentiation into HLC in PVA-used protocol. At 18 days after differentiation, the mature markers, ALB, and CYP3A4 were successfully expressed, while the hepatic progenitor marker, EpCAM, was declined (Fig. 6f). These differentiated HLCs showed MHC I expression similar to intact AM-MSCs (Fig. 6g).

Finally, because the main functions of hepatocytes are protein synthesis and detoxification, we performed to measure albumin secretion and CYP3A4 activity in media cultured AM-HLCs. We confirmed that the secretion of human albumin was significantly increased on day 18 of AM-HLCs than day 0 of undifferentiated cells, but less secreted than PHH control $(P<0.05$, Fig. 6h). The CYP3A4 activity was measured by two independent methods. First, we treated the substrate of CYP3A4, midazolam, to $\mathrm{PHH}$, AM-MSCs, and AM-HLCs for $24 \mathrm{~h}$ and measured the metabolite of midazolam, 1-hydroxymidazolam, using LCESI/MS/MS system [26]. The metabolite was detected in PHH and AM-HLCs groups (Fig. 6i and Fig. S2). Next, we measured the enzyme activity of AM-HLCs using the substrate-luminescence systems. The luminescence was also increased in the $\mathrm{PHH}$ and AM-HLCs groups compared with undifferentiated cells $(P<0.01$, Fig. 6i). But, the activity of the enzyme in AM-HLCs was shown to a lower than PHHs $(P<0.001)$. These results suggest that AM-HPCs with PVA are useful for transplantation into diseased livers because the cells produced albumin and CYP3A4 enzyme, which could catalyze toxic drugs in the liver [44].

Bipotent hepatic progenitor cells provide more efficient rehabilitation than mature hepatocytes after 
a

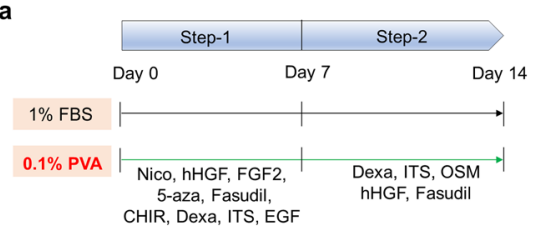

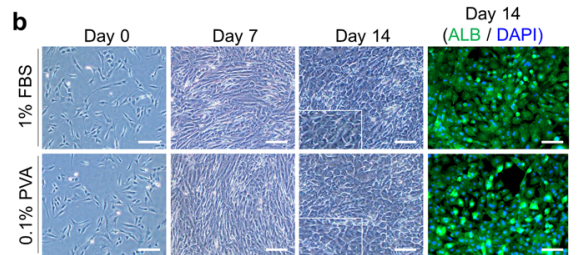

c

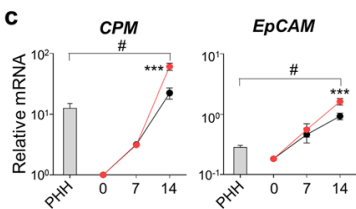

d
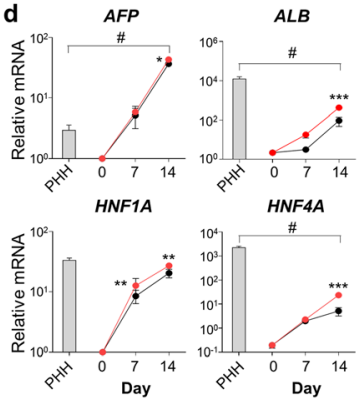

h
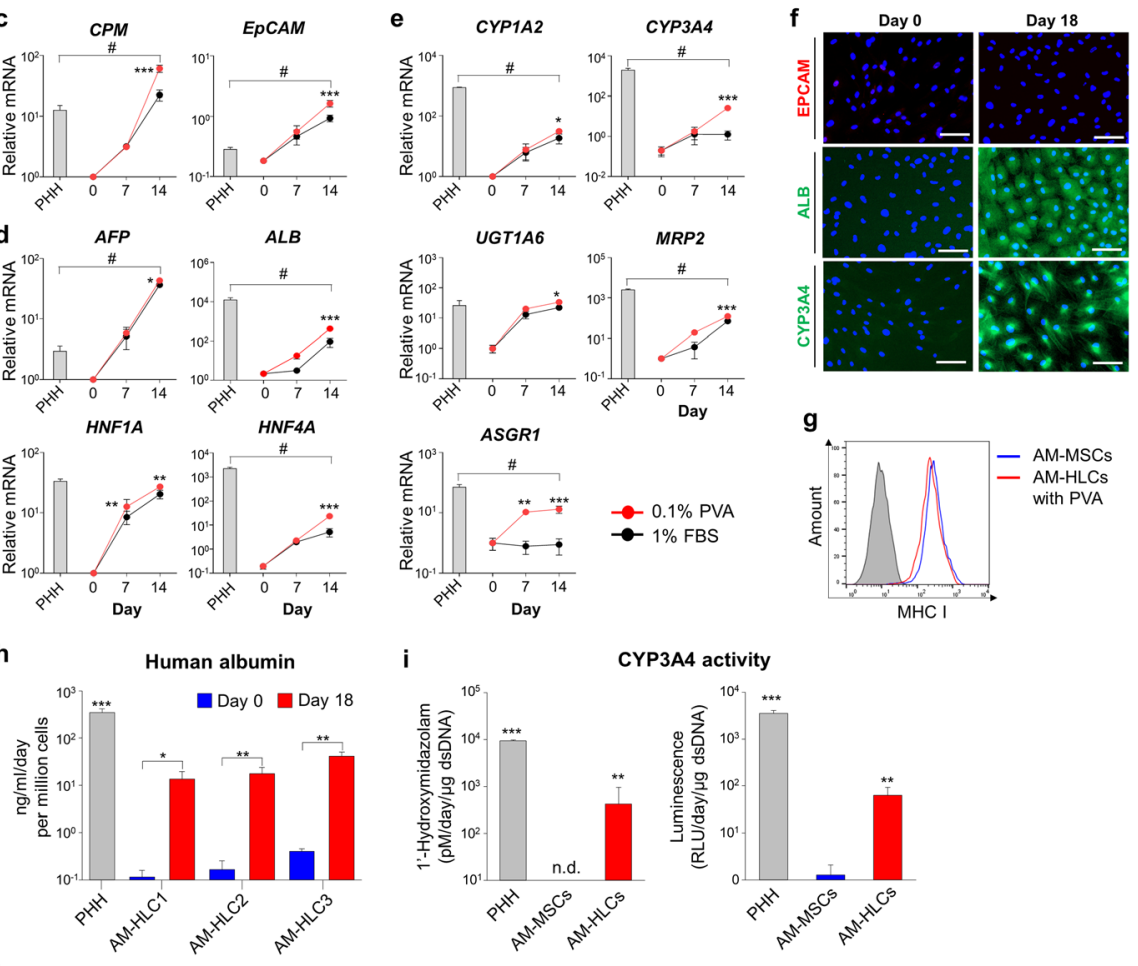

CYP3A4 activity

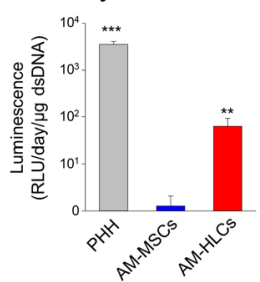

EpCAM
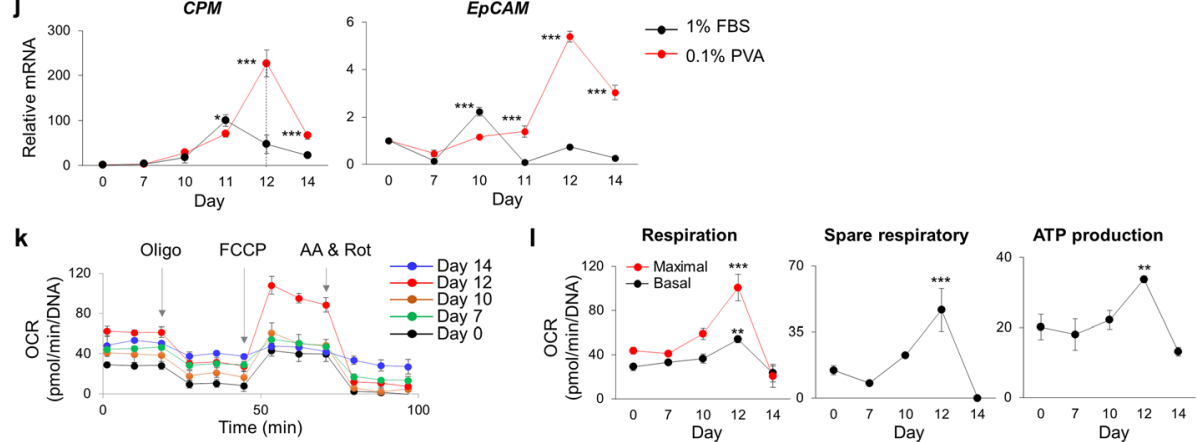

Fig. 6 Comparison of PVA and FBS on hepatic differentiation. a Scheme for hepatic differentiation using $0.1 \%$ PVA or 1\% FBS in the advanced protocol. OSM: Oncostatin M. b Comparison of morphological change during the differentiation when used $0.1 \%$ PVA or $10 \%$ FBS. Scale bar = $200 \mu$ m. c-e The mRNA levels of $\mathbf{c}$ hepatic progenitor markers (CPM and EPCAM), d liver-specific plasma and nuclear protein (AFP, ALB, HNF1A, and HNF4A), and e liver-specific metabolism (CYP1A2, CYP3A4, UGT1A6, MRP2, and ASGR1) in primary human hepatocytes (PHH), PVA, and FBS groups. GAPDH was used as an internal control. \#, $P<0.05$. f The expression of EpCAM, ALB, and CYP3A4 in day 0 (undifferentiated cells) and differentiated cells (hepatocyte-like cells; HLCs) on day 18 after the induction of differentiation. Green, ALB and CYP3A4; Red, EpCAM; Blue, DAPI. Scale bar = 100 Hm. g Comparison of MHC class I expression between AM-MSCs and AM-HLCs with PVA. $\mathbf{h}$ Detection of human albumin secretion in PHH and AM-HLCs, which was derived from three independent AM-MSCs. Day 0 were indicated undifferentiated cells, and Day 18 were indicated differentiated HLCs. i Measurement of CYP3A4 activity using two experiments: Left, detection of 1-Hydroxymidazolam using LC-ESI/MS/MS systems; Right, detection of luciferin density using luminescence systems (PHH: Technical replicate, $n=3$; AM-MSCs and AM-HLCs: Biological replicate, $n=3$ ). n.d., non-detected $\mathbf{j}$ Time-dependent comparison of effects on CPM and EPCAM expression during hepatic differentiation. $\mathbf{k}$ Oxygen consumption rates (OCR) according to the day of hepatic differentiation. Olig: oligomycin, FCCP: carbonyl cyanide 4-(trifluoromethoxy) phenylhydrazone, AA: antimycin A, Rot: rotenone. I Changes of OCR values of basal and maximal respiration, spare respiratory capacity, and ATP production. OCR values were normalized by the DNA concentration. $P$-values $<0.05$ were considered significant. ${ }^{*}, P<0.05 ;{ }^{* *}, P<0.01 ;{ }^{* * *}, P<0.001$ 
transplantation [45]. We have reported that day 14 after hepatic differentiation is the best time for transplanting UCM or LD hepatic progenitors [9]. To decide a suitable transplantation time for the AM-HPCs in vivo, we conducted two experiments to examine the functional properties of the HPCs. First, we investigated the highest expression date of $C P M$ and $E p C A M$, which are critical markers for bi-potential hepatic progenitor cells that can be differentiated into hepatocytes or cholangiocytes [43]. The CPM was most highly expressed in the FBS group on day 11, while in the PVA group it was highest on day 12 $(P<0.01$, Fig. 6j). The EpCAM was most highly expressed on days 10 and 12 in the FBS and PVA groups, respectively $(P<0.001$, Fig. 6 j). Second, we observed mitochondrial oxygen consumption rates (OCR) on days $7,10,12$, and 14 following differentiation using PVA. Overall OCR levels were highest on day 12 (Fig. 6k); more specifically, basal and maximal respiration, spare respiratory capacity, and ATP production were significantly elevated on day 12 $(P<0.01$, Fig. 61). Spare respiratory capacity is the extramitochondrial capacity, which is available under conditions of increased work or stress. Aso, it is considered important for long-term cell survival and function [46]. In conclusion, when PVA is used in hepatic differentiation for xeno-free conditions, it helped increase AM-MSCs maturation into hepatocytes, and mitochondrial functions to support their transplantation efficiency.

In vivo regeneration potential of AM-hepatic progenitor cells The AM-HPCs were transplanted into the mouse liver failure model to see whether the cells could engraft into functional hepatocytes in vivo. To start with, the protocol to induce liver damage in mice was modified with the inclusion of cyclophosphamide monohydrate (CTX) along with thioacetamide (TAA). TAA is widely used in mice to induce liver failure. However, it requires close monitoring and supportive care of the mice due to lethality before research start [47]. In our previous work, half the mice that received the highest doses $(0.2-0.4 \mathrm{mg} / \mathrm{g})$ of TAA died before the start of the study, and the mice were not well-induced at lower doses. Therefore, we needed a more stable mouse model for transplantation studies.

CTX is also toxic to the bone marrow and liver tissue [48]. Based on our previous work, we devised an improved acute liver failure model using $0.025 \mathrm{mg} / \mathrm{g}$ CTX and 0.08 $\mathrm{mg} / \mathrm{g}$ TAA (Fig. 7a). First, we measured the survival rate of the mouse model. A total of 11 mice were inducted into the liver failure model. Two died on day 1 , four died on day 2, and five died on day 3 after induction (Fig. S3b). On day 1 after induction, whole blood was collected from the mouse model and analyzed complete blood counts $(\mathrm{CBC})$ and blood enzyme analyses. The markers for liver damage, alanine aminotransferase (ALT), and aspartate aminotransferase (AST-GOT), and the percentages of granulocytes and lymphocytes were significantly increased in CTX + TAA treated groups compared with the untreated control $(P<0.001$, Fig. 7 b; and $P<0.05$, Table S3). Furthermore, both ALT and AST were significantly more highly expressed in the CTX + TAA group compared with the TAA-only model, while the percentages of granulocytes and lymphocytes were similar liver damage occurred around the hepatic vein during the initial exposure of the liver to the drugs (Fig. S3a). The modified model had a similar effect on acute liver failure as the TAA model, but the Suzuki score tended to be higher (Fig. 7c), and the latter appears to be the historical criterion for assessing liver injury [27]. In conclusion, we decided that cells could transplant 1 day after the induction of the liver failure model, the same as 2 days from the first induction (Fig. 7d).

Finally, to confirm the therapeutic capacity and engraftment of AM-HPCs, we transplanted half a million of AMMSCs and AM-HPCs on different days 11, 12, and 13 into the spleens of the NSG mouse model. One or 3 weeks later, the mice were examined (Fig. 7d). Most of the induced model mice were survival before sacrificing and the histological images of the liver were displayed normal morphology, suggesting that both AM-MSCs and AMHPCs had the therapeutic effect (Fig. S3c). We could not evaluate the comparison of therapeutic effects among groups in this study. However, in human ALB expression, on the day 12 AM-HPC group was detected a higher number of albumin positive cells than other differentiated groups, while the intact AM-MSC group was not detected any positive cells $(P<0.01$, Fig. 7 e and $\mathrm{f})$. Thus, all groups included AM-MSCs showed a therapeutic effect including a paracrine effect $[49,50]$, while as we expected, on day 12 AM-HPCs were a higher engraftment rate with hepatic differentiation in the mouse liver.

To track the transplanted cells, we transfected a green fluorescent protein (GFP) reporter gene to the AM-MSCs and confirmed that the GFP-expressions in AM-MSCs and AM-HPCs (Fig. 6g). Three weeks later, human albumin was detected around the hepatic vein of the mouse liver with histological recovery (Fig. 7h). The ALBpositive cells were co-localized with GFP-expression (Fig. 7i). Additionally, we examined human mtDNA detection in liver tissue. PCR band was shown that there was approximately $6 \%-12 \%$ human mtDNA present in the mouse liver (Fig. 7j). The PCR products were confirmed by Sanger sequencing result in human mtDNA sequence (Fig. 7k and Fig. S3d).

These results suggest that AM-HPCs can successfully engraft in damaged livers and supported regeneration.

\section{Discussion}

We have successfully regenerated hepatocytes in a mouse model using a newly developed method for HPC differentiated from human AM-MSCs (Fig. 8). The advantage of 


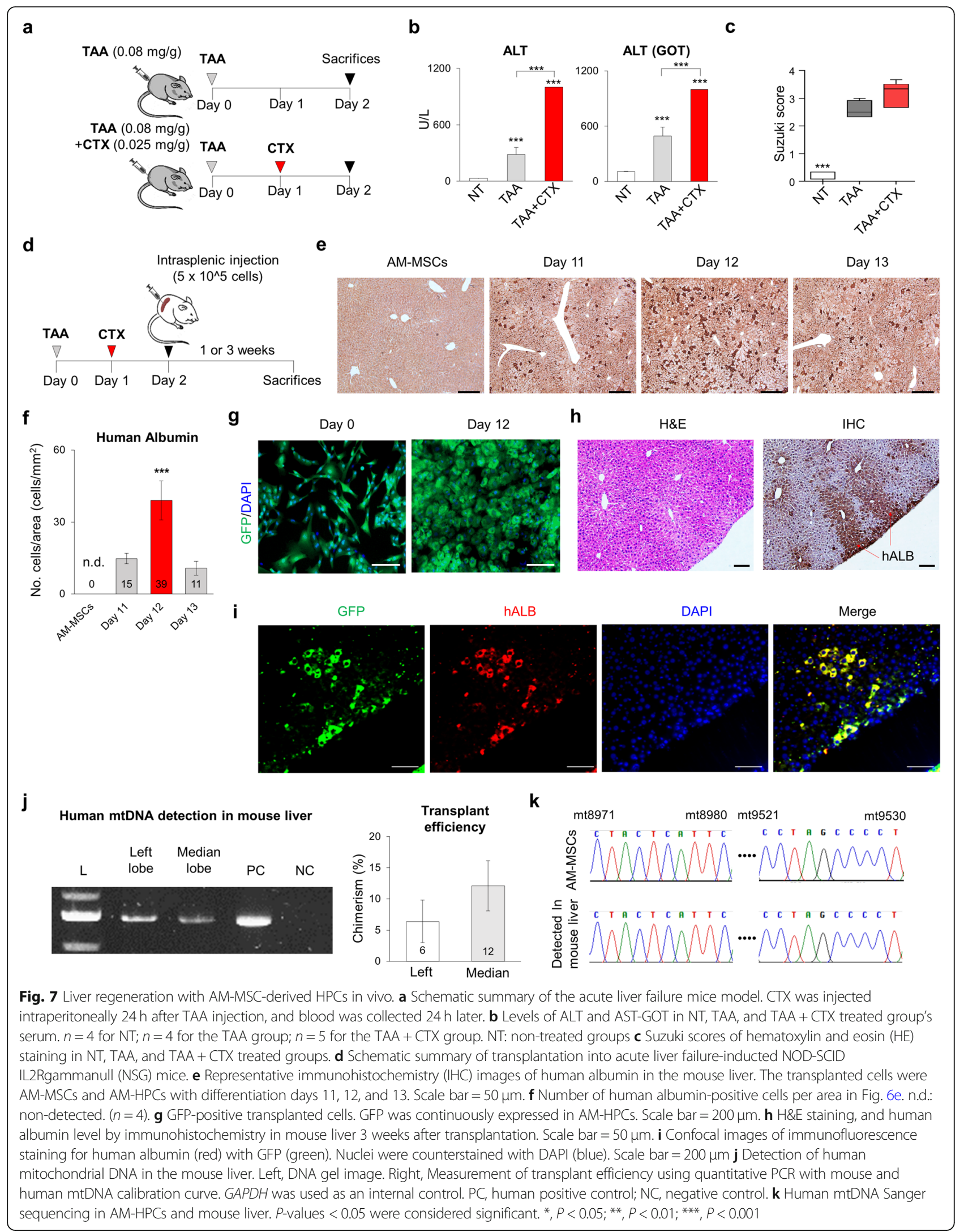


stem cells for cell therapy would be safety, massproducibility, and the ability to select the most effective cells. The ideal stem cells of the future are iPSCs, but there remain issues of safety and insufficient differentiation still exist [51]. The various stem cells derived from neonatal-related tissues differ in yields and differentiation abilities depending on the origin of the tissue and desired differentiated cell type. AM-MSCs are suitable for mass production because of the large amount of original tissue material. Based on our data, if passage 10 is used for therapy, the AM-MSCs established from a single individual could be transplanted into more than 10,000 patients without change of characteristics.

We isolated the AM-MSCs from the amniotic membrane, which generally was isolated epithelial cells [52]. For obtaining amniotic epithelial cells, a collagencoating plate or EGF supplement was needed. We only used 10\% FBS supplemented with bFGF, which could support MSCs characteristics. They were expressed almost 95\% CD105 positive and negative HLA-G (MHC class $1 \mathrm{~b}$ ) [53]. MHC class $1 \mathrm{~b}$ is known as an expression in amnion derived-epithelial cells [29]. Also, EpCAM, which is a positive expression in the epithelium derived from the anionic membrane and hepatic progenitor cells $[53,54]$, was rarely expressed in AM-MSCs.

AM-MSCs can be isolated non-invasively like neonatalrelated tissues, and easily banked depending on their characteristics. AM-MSCs did not express MHC class II and HLA-G but did express HLA-A, B, and C. MHC class I and class II antigens, corresponding to HLA-A, B, C, G, and HLA-DP, DM, DO, DQ, and DR, respectively, have major impacts on graft failure [55]. Matching HLA type or inhibiting MHC expression can reduce or eliminate the use of immunosuppressive drugs, which are unpleasant and can cause side effects [56]. However, additional molecules, such as PD-L1, HLA-E, and CD47, have also been recently identified supporting and describing the lack of immunorecognition upon transplantation in allogenic and xenogenic settings [57]. Therefore, AM-MSCs can be candidate cells for universal donors that have applied gene-editing technology.

The next major hurdle was that somatic stem cells did not have sufficient ability to differentiate into HPCs or HLCs. AM-MSCs had similar characteristics to UCMMSCs in terms of phenotype but differed in gene expression. Thus, we realized that different differentiation protocols might be necessary depending on the origin of the cells. UCM-MSCs was previously reported that the cells expressed hepatocyte-related genes and could easily differentiate into HLCs [58]. Moreover, because of their similar characteristics, UCM-MSCs can be the comparative control of AM-MSC's transcriptome analysis. As a result, the AM-MSCs have lower expression levels of endoderm transcription factors, such as GATA6, KIT, AFP, c-MET,
FGF2, EGF, and c-JUN, and higher expression levels of GSK3.

Because CHIR has been previously used for hepatic differentiation from PSCs [59], we hypothesized that the GSK-3 inhibitor, CHIR, might promote differentiation to HPCs from AM-MSCs. This study showed that CHIR induced the expression of GATA6 and SOX17, which were necessary genes for stem cells to differentiate into hepatocytes. Probably, GSK3 inhibited by CHIR activated GATA6 signaling, which upregulated the Wnt $/ \beta$-catenin pathway, leading to the enhancement of the SOX17 gene [38, 60, 61] (Fig. 8). Therefore, CHIR99021 with the addition of supplements, the advanced protocol conferred robust differentiation ability on the AM-MSCs.

Besides, the ROCK inhibitor, Y-27632, has been used for differentiating hiPSCs to HPCs and reprogramming mature hepatocytes to the HPCs [62, 63]. Fasudil is a known ROCK inhibitor and only approval for clinical and it is similar to Y-27632 for using cell culture and differentiation [40]. Thus, we applied fasudil for differentiating AM-MSCs. The other growth factors and chemicals such as EGF, FGF2, HGF, Dexa, ITS, Nico, 5-aza, and OSM might promote the differentiation of definitive endoderm into hepatic endoderm or hepatic progenitor cells based on previous reports (Table S4).

FBS can contaminate cells during cell culture and differentiation, resulting in the presence of xeno-antigens and infectious agents that can provoke graft-versus-host disease [64]. It can also lead to differences between batches [65]. Hence, FBS must be replaced with an alternative supplement to achieve therapeutic outcomes in patients, but its use is still popular for hepatic differentiation despite the risks associated with transplantation [41]. Polyvinyl alcohol (PVA) is a water-soluble synthetic polymer and has been used as a substitute for bovine serum albumin (BSA) in culture media for mouse preimplantation embryos [66]. It is also used in various human cell expansion and differentiation procedures for therapeutic applications, including hepatic differentiation from PSCs [67-70]. Interestingly, PVA could not only replace FBS but also significantly improved the differentiation to HPCs of AM-MSCs.

As in vivo study models, we induced two chemicals (TAA and CTX) to cause liver failure in mice. In previous studies, TAA is widely used in hepatic disease studies in models. However, TAA-induced models have difficulties controlling because of side effects [47]. For this reason, mouse models were easily dead when TAA was used. In addition, the model was not well induced in a low dose of TAA. Therefore, we used CTX, which is also known as toxic to the liver, and expected that CTX can be affected by the stability and liver damage of the mouse model. Our studies showed that TAA with CTX-induced mice has significantly increased expression of the liver damage 


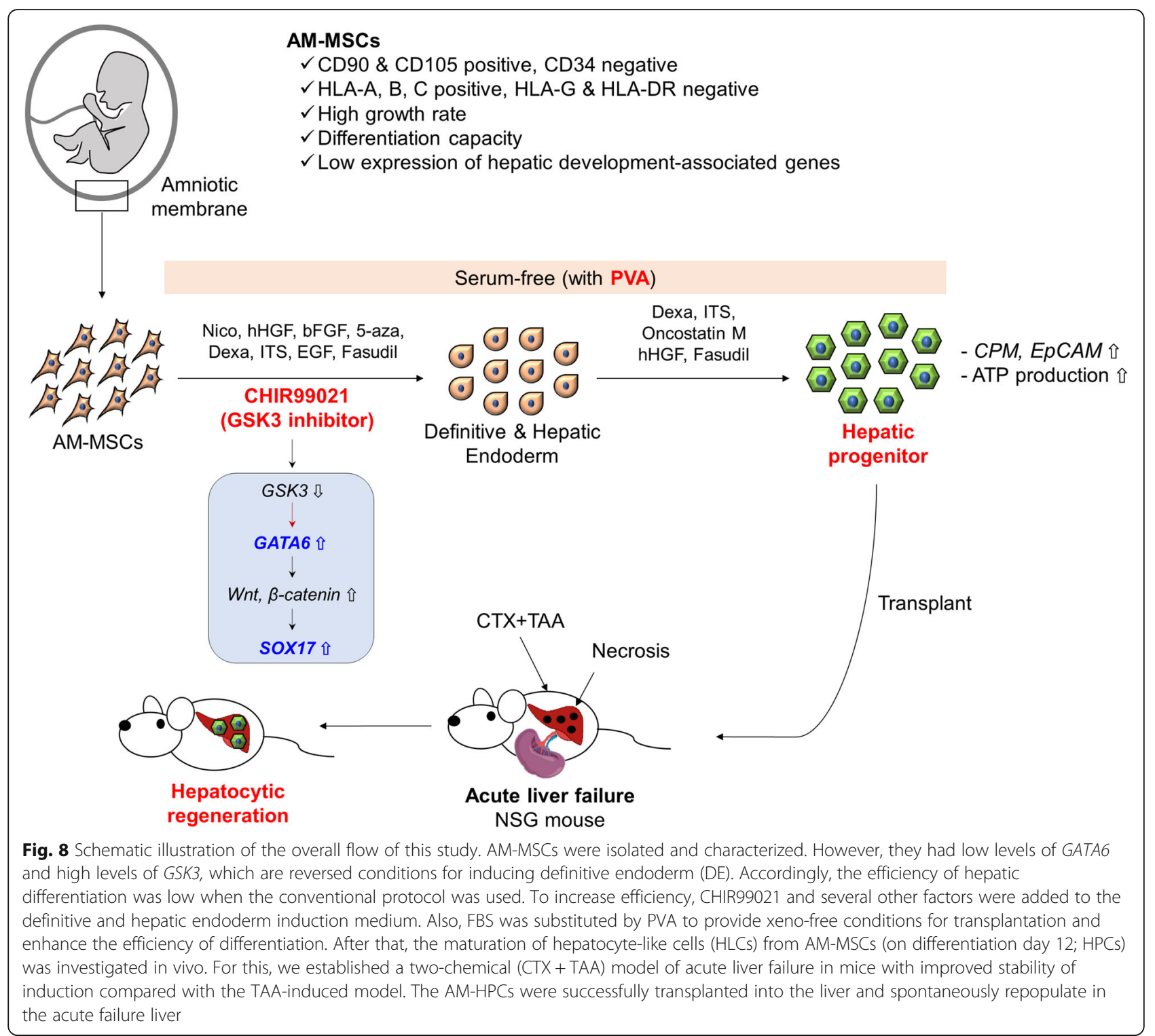

markers (ALT, AST-GOT), and successfully induced necrosis on mouse liver.

To identify optimal transplanting cells, we transplanted AM-MSCs, day 11, day 12, and day 13-differentiated cells into the mouse model. Unlike previous reports with BMMSCs or UCM-MSCs that can differentiate into hepatocyte-like cells in vivo [71, 72], AM-MSCs could not be differentiated in vivo. Probably, since AM-MSCs require additional small molecules such as CHIR99021 for hepatic differentiation in vitro, the cells mainly contributed to supporting the regeneration of damaged liver with mouse's cells instead of differentiation. Even though GSK3 inhibitors were used in a pre-clinical and clinical study for treating cancer [73], it may not be an efficient method to use AM-MSCs along with GSK3 inhibitors for in vivo differentiation due to the side effect or dosage of chemicals
$[74,75]$. On day 12, differentiated cells were the best conditions in terms of the number of human albuminpositive cells in the mouse liver. As we expected this time was matched with higher expression of $C P M$ and $E P C A M$ and OCR levels of mitochondria suggesting useful as biomarkers for transplanting of HPCs.

\section{Conclusions}

This study established a more effective hepatic differentiation protocol for AM-MSCs by analyzing transcriptome profiles. Moreover, our findings suggested that PVA can be a suitable alternative to FBS in the differentiation for clinical trials. Finally, the results of in vivo experimentsupported AM-HPCs can be repopulated in the acutely injured livers and were spontaneously rescued by liver failure. To sum up, this study highlights the fact that AM- 


\section{MSC-derived HPCs are a promising resource for treating acute liver failure.}

\section{Abbreviations}

AM-MSCs: Amnion-derived mesenchymal stem cells; UCM-MSCs: Umbilical cord matrix-derived mesenchymal stem cells; HPCs: Hepatic progenitor cells; HLCs: Hepaotycte-like cells; FBS: Fetal bovine serum; PVA: Polyvinyl alcohol; MHC: Major histocompatibility complex; TAA: Thioacetamide; CTX: Cyclophosphamide monohydrate; MSCs: Mesenchymal stem cells; hLDSCs: Human adult liver-derived stem cells; CPM: Carboxypeptidase M; EpCAM: Epithelial cell adhesion molecule; OCT4: Octamer-binding transcription factor 4; SOX2: Sex-determining region Y-box 2; TNF-a: Tumor necrosis factor-alpha; TGF $\beta$ : Transforming growth factor-beta; KO-AMMSCs: B2M-KO-AM-MSCs; AM-HPCs: AM-MSCs-derived HPCs; UCMHPCs: UCM-MSCs-derived HPCs; AM-HLCs: AM-MSCs-derived hepatocyte-like cells; CHIR: CHIR99021; ALB: Albumin; AFP: Alpha-fetoprotein;

HNF4A: Hepatocyte nuclear factor 4 alpha; HNF1A: Hepatocyte nuclear factor 1 alpha; CYP3A4: Cytochrome P450 3A4; CYP1A2: Cytochrome P450 1A2; UGT1A6: UDP Glucuronosyltransferase Family 1 Member A6; MRP2: Multiple drug resistance-associated protein 2; ASGR1: Asialoglycoprotein receptor 1; OCR: Oxygen consumption rates; ALT: Alanine aminotransferase; ASTGOT: Aspartate aminotransferase; GFP: Green fluorescent protein

\section{Supplementary Information}

The online version contains supplementary material available at https://doi. org/10.1186/s13287-021-02470-y.

Additional file 1: Table S1. Primers used in this work. Table S2. Information on genes associated with hepatic development. Table S3. Complete blood counts and blood enzyme analyses in controls and treated mice. Table S4. Sources of somatic stem cells and their outcomes in terms of hepatic differentiation. Fig. S1 The effect of advanced protocol on UCM-MSCs. a Hepatic gene expression was analyzed 14 days after induction of differentiation. $\mathbf{b}$ Gene expression in day 14 hepatic cells differentiated from different types of adult stem cells; RTqPCR analysis of selected hepatic differentiation genes (ALB, HMFAA, and CPM) in day 14 cells differentiated from PHH, AM-MSCS, UCM-MSCS, LDSC1, and LD-SC2. GAPDH was used as an internal control for RT-qPCR. Pvalues $<0.05$ were considered significant; ns: not significant. *, $P<0.05$; ${ }^{* *}, P<0.01 ;{ }^{* * *}, P<0.001$. Fig. $\mathbf{S 2}$ Chromatogram of LS-ESI/MS/MS profiles in the culture medium of each group after treating midazolam. Red box: the peak of 1-hydroxymidazolam. Fig. $\mathbf{S 3}$ a HE-stained tissue from NT, TAA, and TAA + CTX-treated mice. Scale bar $=50 \mu \mathrm{m}$. NT: non-treated. b Survival rate of CTX + TAA and cell-transplanted groups for 7 days. Number, the number of dead mice. c H\&E staining images after transplanting AM-MSCs and AM-HPCs differentiated days 11, 12, and 13 in the mouse model. Scale bar $=50 \mu \mathrm{m}$. d Sanger sequencing of mtDNA from AM-HPCs and liver tissue from the transplanted mouse. Human AM-HPCs were injected into mouse livers and their partial mitochondrial genomes were analyzed by the Sanger sequencing method. The cells had identical mitochondrial DNA sequences. e Standard curve of human and mouse mtDNA for calculating transfer efficiency.

\section{Acknowledgments}

We are grateful for the use of the facilities of the Flowcytometry core Laboratory of Animal Research core, Comparative Pathology Core, and DMPK core facility at the ConveRgence mEDIcine research center (CREDIT), the Asan Medical Institute of Convergence Science and Technology for use of their equipment, services, and expertise, and Stem cell Center in Asan Medical Center. We also thank Karagozlu Mustafa Zafer for his technical support and the AniCom medical center for the analysis of $\mathrm{CBC}$ and chemistry in mice blood.

\section{Authors' contributions}

J.C and E.K conceived the project, designed the experiments, analyzed all the data, and wrote the manuscript; S.K, B.K, Y.L, G.N.K, and Y.H.S performed the experiments; J.Y.L and S.J.O performed an analysis of metabolites; S.S, J.H M.Y.L, S.R, Y.H.S, and S.H.K provided technical support. All authors read and approved the final manuscript.

\section{Funding}

This research was funded by the Asan Institute for Life Sciences (2019|P0323 and 2019IP796) and the National Research Foundation of Korea (NRF2015K1A4A3046807, NRF-2019M3A9H110358211, and NRF2020M3A9E4036527).

\section{Availability of data and materials}

The datasets used and analyzed during the current study are available from the corresponding author on reasonable request.

\section{Declarations}

Ethics approval and consent to participate

Ethics approval and consent to human participation in the study were approved by the Institutional Review Board (IRB) of Asan Medical Center (Seoul, Korea; 2015-0303). All mouse study was approved by the Asan Institutional Animal Care and Use Committee (IACUC, 2018-12-167, 2019-12-062, and 2020-02-208).

\section{Consent for publication}

Not applicable.

\section{Competing interests}

No conflicts of interest exist for any of the authors.

\section{Author details}

'Department of Medical Science, Asan Medical Institute of Convergence Science and Technology (AMIST), University of Ulsan College of Medicine, Asan Medical Center, Seoul 05505, South Korea. ${ }^{2}$ Stem Cell Center, Asan Institute for Life Sciences, Asan Medical Center, Seoul 05505, South Korea. ${ }^{3}$ Present Address: Center for Embryo \& Stem Cell Research, CHA Advanced Research Institute and Department of Biomedical Science, CHA University, Pocheon-si, Gyeonggi 13488, South Korea. ${ }^{4}$ Convergence Medicine Research Center, Asan Institute for Life Sciences, Asan Medical Center, Seoul 05505, South Korea. ${ }^{5}$ Department of Obstetrics and Gynecology, University of Ulsan College of Medicine, Asan Medical Center, Seoul 05505, South Korea. ${ }^{6}$ Asan Institute for Life Sciences, Asan Medical Center and Department of Convergence Medicine, College of Medicine, University of Ulsan, Seoul 05505, South Korea.

Received: 24 November 2020 Accepted: 22 June 2021

Published online: 12 November 2021

\section{References}

1. Lee WM. Acute liver failure. Seminars in respiratory and critical care medicine: Thieme Medical Publishers; 2012.

2. Kotlyar DS, Burke A, Campbell MS, Weinrieb RM. A critical review of candidacy for orthotopic liver transplantation in alcoholic liver disease. Am J Gastroenterol. 2008;103(3):734-43 quiz 44.

3. Burra P, Bizzaro D, Ciccocioppo R, Marra F, Piscaglia AC, Porretti L, et al. Therapeutic application of stem cells in gastroenterology: an up-date. World J Gastroenterol. 2011:17(34):3870-80.

4. Hossein Aghdaie M, Geramizadeh B, Azarpira N, Esfandiari E, Darai M, Rahsaz $M$, et al. Hepatocyte isolation from unused/rejected livers for transplantation: initial step toward hepatocyte transplantation, the first experience from Iran. Hepat Mon. 2013;13(8):e10397-e.

5. Sauer V, Roy-Chowdhury N, Guha C, Roy-Chowdhury J. Induced pluripotent stem cells as a source of hepatocytes. Curr Pathobiol Rep. 2014;2(1):11-20.

6. Baharvand H, Hashemi SM, Shahsavani M. Differentiation of human embryonic stem cells into functional hepatocyte-like cells in a serum-free adherent culture condition. Differentiation. 2008;76(5):465-77.

7. Wu XB, Tao R. Hepatocyte differentiation of mesenchymal stem cells. Hepatobiliary Pancreat Dis Int. 2012;11(4):360-71.

8. Miyajima A, Tanaka M, Itoh T. Stem/progenitor cells in liver development, homeostasis, regeneration, and reprogramming. Cell Stem Cell. 2014;14(5): 561-74.

9. Lee J, Choi J, Kang S, Kim J, Lee R, So S, et al. Hepatogenic potential and liver regeneration effect of human liver-derived mesenchymal-like stem cells. Cells. 2020;9(6).

10. Rajala K, Lindroos B, Hussein SM, Lappalainen RS, Pekkanen-Mattila M, Inzunza J, et al. A defined and Xeno-free culture method enabling the 
establishment of clinical-grade human embryonic, induced pluripotent and adipose stem cells. PLoS One. 2010;5(4):e10246.

11. Chen J-Y, Mou X-Z, Du X-C, Xiang C. Comparative analysis of biological characteristics of adult mesenchymal stem cells with different tissue origins. Asian Pac J Trop Med. 2015;8(9):739-46.

12. Pogozhykh O, Pogozhykh D, Neehus A-L, Hoffmann A, Blasczyk R, Müller T. Molecular and cellular characteristics of human and non-human primate multipotent stromal cells from the amnion and bone marrow during long term culture. Stem Cell Res Ther. 2015;6(1):150

13. Lee H-J, Jung J, Cho KJ, Lee CK, Hwang S-G, Kim GJ. Comparison of in vitro hepatogenic differentiation potential between various placenta-derived stem cells and other adult stem cells as an alternative source of functional hepatocytes. Differentiation. 2012;84(3):223-31.

14. Lindenmair A, Hatlapatka T, Kollwig G, Hennerbichler S, Gabriel C, Wolbank $S$, et al. Mesenchymal stem or stromal cells from amnion and umbilical cord tissue and their potential for clinical applications. Cells. 2012;1(4):1061-88.

15. Kang NH, Hwang KA, Kim SU, Kim YB, Hyun SH, Jeung EB, et al. Potential antitumor therapeutic strategies of human amniotic membrane and amniotic fluid-derived stem cells. Cancer Gene Ther. 2012;19(8):517-22.

16. Zhao $\mathrm{P}$, Ise $\mathrm{H}$, Hongo M, Ota M, Konishi I, Nikaido T. Human amniotic mesenchymal cells have some characteristics of cardiomyocytes. Transplantation. 2005;79(5):528-35.

17. Ota M, Takagaki $\mathrm{K}$, Takaoka S, Tanemura H, Urushihata N. A new method to confirm the absence of human and animal serum in mesenchymal stem cell culture media. Int J Med Sci. 2019;16(8):1102-6.

18. Jung S, Panchalingam KM, Rosenberg L, Behie LA. Ex vivo expansion of human mesenchymal stem cells in defined serum-free media. Stem Cells Int. 2012;2012:123030.

19. Koivisto H, Hyvärinen M, Strömberg A-M, Inzunza J, Matilainen E, Mikkola M, et al. Cultures of human embryonic stem cells: serum replacement medium or serum-containing media and the effect of basic fibroblast growth factor. 2004:9(3):330-7.

20. Inzunza J, Gertow K, Strömberg MA, Matilainen E, Blennow E, Skottman H, et al. Derivation of human embryonic stem cell lines in serum replacement medium using postnatal human fibroblasts as feeder cells. 2005;23(4):544-9.

21. Battula VL, Bareiss PM, Treml S, Conrad S, Albert I, Hojak S, et al. Human placenta and bone marrow derived MSC cultured in serum-free, b-FGFcontaining medium express cell surface frizzled-9 and SSEA-4 and give rise to multilineage differentiation. 2007;75(4):279-91.

22. Park YH, Yun JI, Han NR, Park HJ, Ahn JY, Kim C, et al. Mass production of early-stage bone-marrow-derived mesenchymal stem cells of rat using gelatin-coated matrix. Biomed Res Int. 2013;2013:347618.

23. Kim J, Piao Y, Pak YK, Chung D, Han YM, Hong JS, et al. Umbilical cord mesenchymal stromal cells affected by gestational diabetes mellitus display premature aging and mitochondrial dysfunction. Stem Cells Dev. 2015;24(5): 575-86.

24. Zhang Q, Shi S, Liu Y, Uyanne J, Shi Y, Shi S, et al. Mesenchymal stem cells derived from human gingiva are capable of immunomodulatory functions and ameliorate inflammation-related tissue destruction in experimental colitis. J Immunol. 2009;183(12):7787.

25. Galetin A, Ito K, Hallifax D, Houston JB. CYP3A4 substrate selection and substitution in the prediction of potential drug-drug interactions. J Pharmacol Exp Ther. 2005;314(1):180.

26. Lee KS, Kim SK. Direct and metabolism-dependent cytochrome P450 inhibition assays for evaluating drug-drug interactions. J Appl Toxicol. 2013; 33(2):100-8.

27. Suzuki S, Toledo-Pereyra LH, Rodriguez FJ, Cejalvo D. Neutrophil infiltration as an important factor in liver ischemia and reperfusion injury. Modulating effects of FK506 and cyclosporine. Transplantation. 1993;55(6):1265-72.

28. Tzur A, Moore JK, Jorgensen P, Shapiro HM, Kirschner MW. Optimizing optical flow cytometry for cell volume-based sorting and analysis. PLoS One. 2011;6(1):e16053.

29. Strom SC, Gramignoli R. Human amnion epithelial cells expressing HLA-G as novel cell-based treatment for liver disease. Hum Immunol. 2016;77(9):734-9.

30. Tsai CC, Su PF, Huang YF, Yew TL, Hung SC. Oct4 and Nanog directly regulate Dnmt1 to maintain self-renewal and undifferentiated state in mesenchymal stem cells. Mol Cell. 2012;47(2):169-82.

31. Suzuki K, Murtuza B, Beauchamp JR, Brand NJ, Barton PJR, Varela-Carver $A$, et al. Role of interleukin-1 beta in acute inflammation and graft death after cell transplantation to the heart. Circulation. 2004;110(11 Suppl 1): |1219-24.
32. Boyer LA, Lee TI, Cole MF, Johnstone SE, Levine SS, Zucker JP, et al. Core transcriptional regulatory circuitry in human embryonic stem cells. Cell. 2005;122(6):947-56.

33. Kabat M, Bobkov I, Kumar S, Grumet M. Trends in mesenchymal stem cell clinical trials 2004-2018: is efficacy optimal in a narrow dose range? 2020; 9(1):17-27.

34. Zetsche B, Heidenreich M, Mohanraju P, Fedorova I, Kneppers J, DeGennaro EM, et al. Multiplex gene editing by CRISPR-Cpf1 using a single crRNA array. Nat Biotechnol. 2017;35(1):31-4

35. Vonderheide $\mathrm{RH}$. CD47 blockade as another immune checkpoint therapy for cancer. Nat Med. 2015;21(10):1122-3.

36. Morrison G, Scognamiglio R, Trumpp A, Smith A. Convergence of cMyc and B-catenin on Tcf7l1 enables endoderm specification. 2016;35(3):356-68.

37. Yang J, Lu P, Li M, Yan C, Zhang T, Jiang W. GATA6-AS1 regulates GATA6 expression to modulate human endoderm differentiation. Stem Cell Rep. 2020;15(3):694-705.

38. Duda P, Akula SM, Abrams SL, Steelman LS, Martelli AM, Cocco L, et al. Targeting GSK3 and associated signaling pathways involved in cancer. Cells. 2020;9(5).

39. Michalopoulos GK, Bowen WC, Mulè K, Luo J. HGF-, EGF-, and dexamethasone-induced gene expression patterns during formation of tissue in hepatic organoid cultures. Gene Expr. 2003;11(2):55-75.

40. So S, Lee Y, Choi J, Kang S, Lee J-Y, Hwang J, et al. The rho-associated kinase inhibitor fasudil can replace Y-27632 for use in human pluripotent stem cell research. PLoS One. 2020;15(5):e0233057.

41. Afshari A, Shamdani S, Uzan G, Naserian S, Azarpira N. Different approaches for transformation of mesenchymal stem cells into hepatocyte-like cells. Stem Cell Res Ther. 2020;11(1):54.

42. Zabulica M, Srinivasan RC, Vosough M, Hammarstedt C, Wu T, Gramignoli R, et al. Guide to the assessment of mature liver gene expression in stem cellderived hepatocytes. Stem Cells Dev. 2019;28(14):907-19.

43. Kido T, Koui Y, Suzuki K, Kobayashi A, Miura Y, Chern EY, et al. CPM is a useful cell surface marker to isolate expandable bi-potential liver progenitor cells derived from human iPS cells. Stem Cell Rep. 2015;5(4):508-15.

44. Drocourt L, Ourlin J-C, Pascussi J-M, Maurel P, Vilarem M-JJJOBC. Expression of cyp3a4, cyp2b6, andcyp2c9 is regulated by the vitamin d receptor pathway in primary human hepatocytes. 2002;277(28):25125-32.

45. Sell S. The role of progenitor cells in repair of liver injury and in liver transplantation. 2001;9(6):467-82.

46. Choi SW, Gerencser AA, Nicholls DG. Bioenergetic analysis of isolated cerebrocortical nerve terminals on a microgram scale: spare respiratory capacity and stochastic mitochondrial failure. J Neurochem. 2009;109(4):1179-91.

47. Wallace MC, Hamesch K, Lunova M, Kim Y, Weiskirchen R, Strnad P, et al Standard operating procedures in experimental liver research: thioacetamide model in mice and rats. Lab Anim. 2015;49(1 Suppl):21-9.

48. Bhat N, Kalthur SG, Padmashali S, Monappa VJE. Toxic effects of different doses of cyclophosphamide on live. 2018;28(6).

49. Willenbring H, Bailey AS, Foster M, Akkari Y, Dorrell C, Olson S, et al. Myelomonocytic cells are sufficient for therapeutic cell fusion in liver. Nat Med. 2004;10(7):744-8

50. Hoofnagle MH, Wamhoff BR, Owens GK. Lost in transdifferentiation. J Clin Invest. 2004;113(9):1249-51.

51. Andrews PW, Ben-David U, Benvenisty N, Coffey P, Eggan K, Knowles BB, et al. Assessing the safety of human pluripotent stem cells and their derivatives for clinical applications. Stem Cell Rep. 2017;9(1):1-4

52. Miki T, Lehmann T, Cai H, Stolz DB, Strom SC. Stem cell characteristics of amniotic epithelial cells. Stem Cells (Dayton, Ohio). 2005;23(10):1549-59.

53. Motedayyen H, Esmaeil N, Tajik N, Khadem F, Ghotloo S, Khani B, et al. Method and key points for isolation of human amniotic epithelial cells with high yield, viability and purity. BMC Res Notes. 2017;10(1):552.

54. Dollé L, Theise ND, Schmelzer E, Boulter L, Gires O, van Grunsven LA. EpCAM and the biology of hepatic stem/progenitor cells. Am J Physiol Gastrointest Liver Physiol. 2015;308(4):G233-50.

55. Ayala García MA, González Yebra B, López Flores AL, Guaní GE. The major histocompatibility complex in transplantation. J Transp Secur. 2012;2012: 842141

56. Zakrzewski JL, van den Brink MRM, Hubbell JA. Overcoming immunological barriers in regenerative medicine. Nat Biotechnol. 2014;32(8):786-94.

57. Han X, Wang M, Duan S, Franco PJ, Kenty JH-R, Hedrick P, et al. Generation of hypoimmunogenic human pluripotent stem cells. Proc Natl Acad Sci. 2019;116(21):10441. 
58. Campard D, Lysy PA, Najimi M, Sokal EM. Native umbilical cord matrix stem cells express hepatic markers and differentiate into hepatocyte-like cells. Gastroenterology. 2008;134(3):833-48.

59. Hannoun Z, Steichen C, Dianat N, Weber A, Dubart-Kupperschmitt A. The potential of induced pluripotent stem cell derived hepatocytes. J Hepatol. 2016;65(1):182-99.

60. Tiyaboonchai A, Cardenas-Diaz FL, Ying L, Maguire JA, Sim X, Jobaliya C, et al. GATA6 plays an important role in the induction of human definitive endoderm, development of the pancreas, and functionality of pancreatic $\beta$ cells. Stem Cell Rep. 2017;8(3):589-604.

61. Huang J, Guo X, Li W, Zhang H. Activation of Wnt/B-catenin signalling via GSK3 inhibitors direct differentiation of human adipose stem cells into functional hepatocytes. Sci Rep. 2017;7:40716.

62. Yanagida A, Ito K, Chikada H, Nakauchi H, Kamiya A. An in vitro expansion system for generation of human iPS cell-derived hepatic progenitor-like cells exhibiting a bipotent differentiation potential. PLoS One. 2013;8(7): e67541.

63. Katsuda T, Kawamata M, Hagiwara K, Takahashi R-U, Yamamoto Y, Camargo FD, et al. Conversion of terminally committed hepatocytes to culturable bipotent progenitor cells with regenerative capacity. Cell Stem Cell. 2017; 20(1):41-55.

64. Oikonomopoulos A, van Deen WK, Manansala A-R, Lacey PN, Tomakili TA, Ziman A, et al. Optimization of human mesenchymal stem cell manufacturing: the effects of animal/xeno-free media. Sci Rep. 2015;5(1): 16570.

65. Haque N, Kasim NHA, Rahman MT. Optimization of pre-transplantation conditions to enhance the efficacy of mesenchymal stem cells. Int J Biol Sci. 2015;11(3):324-34.

66. Biggers J, Summers M, McGinnis L. Polyvinyl alcohol and amino acids as substitutes for bovine serum albumin in culture media for mouse preimplantation embryos. Hum Reprod Update. 1997;3(2):125-35.

67. Wilkinson AC, Ishida R, Kikuchi M, Sudo K, Morita M, Crisostomo RV, et al. Long-term ex vivo haematopoietic-stem-cell expansion allows nonconditioned transplantation. Nature. 2019;571(7763):117-21.

68. Stocco E, Barbon S, Lora L, Grandi F, Sartore L, Tiengo C, et al. Partially oxidized polyvinyl alcohol conduitfor peripheral nerve regeneration. Sci Rep. 2018;8(1):604.

69. Burridge PW, Thompson S, Millrod MA, Weinberg S, Yuan X, Peters A, et al. A universal system for highly efficient cardiac differentiation of human induced pluripotent stem cells that eliminates interline variability. 2011;6(4).

70. Nishimura T, Hsu I, Martinez-Krams DC, Nakauchi Y, Majeti R, Yamazaki S, et al. Use of polyvinyl alcohol for chimeric antigen receptor T-cell expansion. Exp Hematol. 2019;80:16-20.

71. Yuan L, Jiang J, Liu X, Zhang Y, Zhang L, Xin J, et al. HBV infection-induced liver cirrhosis development in dual-humanised mice with human bone mesenchymal stem cell transplantation. Gut. 2019;68(11):2044.

72. Zhang G-Z, Sun H-C, Zheng L-B, Guo J-B, Zhang X-LJW. In vivo hepatic differentiation potential of human umbilical cord-derived mesenchymal stem cells: therapeutic effect on liver fibrosis/cirrhosis. 2017;23(46):8152.

73. Augello G, Emma MR, Cusimano A, Azzolina A, Montalto G, McCubrey JA, et al. The role of GSK-3 in cancer immunotherapy: GSK-3 inhibitors as a new frontier in cancer treatment. Cells. 2020;9(6).

74. Kaiser M, Edemir B. Lithium chloride and GSK3 inhibition reduce aquaporin2 expression in primary cultured inner medullary collecting duct cells due to independent mechanisms. Cells. 2020;9(4).

75. Gray JE, Infante JR, Brail LH, Simon GR, Cooksey JF, Jones SF, et al. A first-inhuman phase I dose-escalation, pharmacokinetic, and pharmacodynamic evaluation of intravenous LY2090314, a glycogen synthase kinase 3 inhibitor, administered in combination with pemetrexed and carboplatin. Investig New Drugs. 2015;33(6):1187-96,

\section{Publisher's Note}

Springer Nature remains neutral with regard to jurisdictional claims in published maps and institutional affiliations.

Ready to submit your research? Choose BMC and benefit from:

- fast, convenient online submission

- thorough peer review by experienced researchers in your field

- rapid publication on acceptance

- support for research data, including large and complex data types

- gold Open Access which fosters wider collaboration and increased citations

- maximum visibility for your research: over $100 \mathrm{M}$ website views per year

At $\mathrm{BMC}$, research is always in progress.

Learn more biomedcentral.com/submissions 